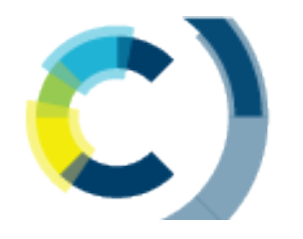

\title{
Polymer
Chemistry
}

\section{Nano-assemblies with Core-Forming Hydrophobic Polypeptide via Polymerization-Induced Self-Assembly (PISA)}

\begin{tabular}{|r|l|}
\hline Journal: & Polymer Chemistry \\
\hline Manuscript ID & Draft \\
\hline Article Type: & Paper \\
\hline Author: & n/a \\
\hline Complete List of Authors: & $\begin{array}{l}\text { Dao, Tuyen; University of Montpellier, IEM } \\
\text { Vezenkov, Lubomir; ENSCM, IBMM team 9; } \\
\text { Subra, Gilles; Institut des Biomolecules Max Mousseron, } \\
\text { Ladmiral, Vincent; Institut Charles Gerhardt - UMR(CNRS), Ingénierie et } \\
\text { Architectures Macromoléculaires } \\
\text { Semsarilar, Mona; University of Montpellier, IEM }\end{array}$ \\
\hline
\end{tabular}

\section{SCHOLARONE Manuscripts}


Mona SEMSARILAR, PhD

CNRS Researcher

Institut Européen des Membranes

Université Montpellier

2 place E. Bataillon

34095 MONTPELLIER Cedex 5, France

Mail : mona.semsarilar@umontpellier.fr

Montpellier, 01/06/2020

Dear Editor,

Please find attached our paper entitled "Nano-assemblies with Core-Forming Hydrophobic Polypeptide via Polymerization-Induced Self-Assembly (PISA)" for consideration for publication as a full article in Polymer Chemistry, Polymerization-Induced Self-Assembly (PISA) special issue.

In recent years polymerization-induced self-assembly (PISA) mediated by reversible addition-fragmentation chain transfer (RAFT) dispersion polymerization has changed the way synthetic chemists prepare and self-assemble block copolymers. PISA is indeed a powerful and versatile technique for the synthesis and self-assembly of a wide range of block copolymer nano-objects of controllable size, morphology, and surface functionality.

The polymers used in PISA have so far been for the vast majority unable to develop supramolecular interactions. Apart from the recent report of Rieger et al (https://doi.org/10.1002/anie.201809370), there are no other study on PISA and supramolecular interactions. In the present manuscript, we take a new approach to the established PISA procedure, and we prepare peptide-polymer hybrids. Two new monomers bearing short peptide sequences capable of self-assembling due to pi-pi stacking and $\mathrm{H}$ bonding were synthesized. We demonstrate that insertion of only few units of these selfassembling peptide (SAP) monomers in the core-forming block of a typical PISA formulation (poly (glycerol monomethacrylate) (PGMA) stabilizing first block followed by dispersion polymerization of 2-hydroxypropyl methacrylate (HPMA)) completely changes the selfassembly regime of this diblock copolymers. New morphologies were observed thus underlining the decisive influence of the SAP monomers.

We believe that the special PISA issue in Polymer Chemistry is an ideal platform to report these exciting new results, which should be of considerable interest to polymer chemists as well as material scientists. We would thus be very grateful if you could consider our manuscript for publication.

On behalf of all the co-authors,

Yours sincerely,

Mona Semsarilar

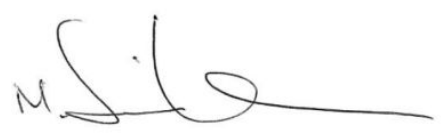




\title{
Nano-assemblies with Core-Forming Hydrophobic Polypeptide via Polymerization-Induced Self-Assembly (PISA)
}

Received 00th January 20xx, Accepted 00th January 20xx DOI: $10.1039 / \times 0 \times x 00000 x$

\author{
T. P. Tuyen Dao ${ }^{a, b, c}$, Lubomir Vezenkovc, Gilles Subrac, Vincent Ladmiral ${ }^{b}$, Mona Semsarilar ${ }^{a^{*}}$
}

\begin{abstract}
The aim of this study is to produce self-assembled structures with hydrophobic polypeptide cores via Reversible Addition-Fragmentation chain Transfer (RAFT) - mediated Polymerisation-Induced Self-Assembly (PISA). Hydrophilic poly(glycerol monomethacrylate) macromolecular chain transfer agents (PGMA mCTAs) were used to polymerize the selfassembling peptide monomers, resulting in the formation of diblock copolymer nano objects. Methacrylamide derivatives containing self-assembling tripeptide; MAm-GFF (MAm-Gly-Phe-Phe- $\mathrm{NH}_{2}$ ) and MAm-FGD (MAm-Phe-Gly-Asp-NH $\mathrm{NH}_{2}$ were used as hydrophobic monomers. The self-assembling behaviours of these monomers mainly derive from the interactions of the phenylalanine residues, however their difference in hydrophobicity required different polymerization conditions. MAm-GFF was polymerized in the presence of organic solvent (ethanol or acetonitrile), under either dispersion or emulsion polymerization, while MAm-FGD was polymerized under aqueous dispersion conditions. PGMA- $b$-P(MAm-FGD) obtained from aqueous PISA typically formed fibrous structures while a range of morphologies such as fibre-, flake-, leaflike or spherical vesicles were obtained for PGMA-b-P(MAm-GFF) depending on the copolymer composition and solvent used. In all cases the peptides self-assembling core had a crucial influence on the final morphologies.
\end{abstract}

\section{Introduction}

Self-assembled nanostructures based on polypeptide-polymer hybrid are interesting biomaterials with potential significant impacts in applied biology and medicine. Compared to pure polymeric nanoparticles, these structures could present increased biocompatibility and biofunctionality typical of the peptide sequences, ${ }^{1-3}$ in addition to the robustness and functional diversity conferred by the polymer chains. Moreover, the range of selfassembled peptide-containing structures is more diverse than that of polymer nano-objects. ${ }^{4-6}$ They can form more complex supramolecular assemblies such as nano-fibers, ribbons, tapes, tubes, wires or rods. ${ }^{6-15}$ In particular, since the molecular selforganization of these structures is mainly attributed to weak interactions such as electrostatic forces, hydrophobic interactions, $\pi-\pi$ stacking and hydrogen bonding, ${ }^{16}$ these structures can largely vary in both shape and size depending on internal or external stimuli ( $\mathrm{pH}$, temperature, ionic strength, solvents...). ${ }^{17-19}$ The diversity and versatility of peptide-based nanostructures allow them to be potentially used in different biomedical fields such as biosensors, tissue engineering, or drug delivery. . $^{40-23}$

\footnotetext{
a. Institut Européen des Membranes, IEM, Univ Montpellier, CNRS, ENSCM, Montpellier, France

b. Institut Charles Gerhardt Montpellier, ICGM, Univ Montpellier, CNRS, ENSCM, Montpellier, France

Institut des Biomolécules Max Mousseron, IBMM, Univ Montpellier, CNRS, ENSCM, Montpellier, France

Electronic Supplementary Information (ESI) available: NMR spectra, SEC curves, DLS data, digital photos taken, Summary Table for all obtaining products. See
} DOI: $10.1039 / x 0 x x 00000 x$
Besides the conventional self-assembly strategies using purified and isolated amphiphilic block copolymers, polymerization-induced selfassembly (PISA) has been shown to be a powerful polymer selfassembly method over the last decade and as such has received considerable interest. ${ }^{24}, 25$ PISA strategy is fast, eliminating timeconsuming steps such as isolation/ purification and redispersion of the amphiphilic polymers since it proceeds via the simultaneous formation and self-assembly of the amphiphilic block copolymers. ${ }^{26}$ While the conventional post-polymerization methods provide dilute suspensions of nanoparticles (ca. $1 \% \mathrm{w} / \mathrm{w}$ ), PISA generates nanoparticles at much higher concentrations (up to $50 \% \mathrm{w} / \mathrm{w}$ as reported in recent studies). ${ }^{27}, 28$ Moreover, PISA works well under either dispersion ${ }^{29-33}$ or emulsion polymerization conditions ${ }^{34-37}$ and in a wide range of solvents. ${ }^{38-45}$ Although the use of PISA is drastically growing due to its advantages, most reports show relatively simple self-assembled morphologies (spheres, worms and vesicles). ${ }^{25}$ Inspired by the properties of peptide-based nanostructures as well as PISA approach, we have recently reported the first example of PISA nano-objects derived from self-assembling peptide (SAP) containing polymer. ${ }^{46}$ The SAP monomer used in this study (MAm-GFF), was a methacrylamide-functionalized GFF tripeptide (GFF = Glycine-Phenylalanine-Phenylalanine). The tripeptide moieties were incorporated along with glycerol monomethacrylate (GMA) in the stabilizing block which was successfully chain extended under PISA conditions with poly(2hydroxypropyl methacrylate) (PHPMA). The resulting $\mathrm{P}\left(\mathrm{GMA}_{65}\right.$-stat$(\mathrm{MAm}-\mathrm{GFF})_{7}$ )- $b$-PHPMA 28 diblock copolymer formed fibrous structures in water. Herein, the same peptide methacrylamide was used but as precursor of the core-forming block. PISA formulations with core-forming block composed of copolymer of this SAP 
methacrylamide and a solvophilic monomer (GMA or HPMA) were also examined. Moreover, a new tripeptide-containing methacrylamide, (MAm-FGD) based on the phenylalanine- glycineaspartic acid SAP sequence was also studied. As for MAm-GFF, the self-assembly property of MAm-FGD is also attributed to the phenylalanine residue. However MAm-FGD is slightly less hydrophobic than MAm-GFF at physiological $\mathrm{pH}$, and thus allows the use of different PISA conditions. All the synthetic approaches of this work are summarized in Scheme 1.

\section{Experimental section}

\section{Materials}

Fmoc-amino acid derivatives (Fmoc-Phe-OH, Fmoc-Gly-OH, FmocAsp(tBu)-OH), HATU (1-[bis(dimethylamino)methylene]-1H-1,2,3triazolo[4,5-b]pyridinium 3-oxide hexafluorophosphate) and polystyrene Fmoc Rink Amide resins (100-200 mesh) with a loading of $0.94 \mathrm{mmol} / \mathrm{g}$ were purchased from Iris Biotech $\mathrm{GmbH}$. Methacrylic acid, piperidine, $N, N$-diisopropylethylamine (DIEA), trifluoroacetic acid (TFA), triisopropylsilane (TIS), glycerol monomethacrylate (GMA), 2-hydroxypropyl methacrylate (HPMA), 4,4'-azobis(4-cyanopentanoic acid) (ACVA) and all organic solvents were purchased from Sigma-Aldrich. The NMR deuterated solvents (DMSO-d6, methanol-d4 and $\mathrm{D}_{2} \mathrm{O}$ ) were purchased from Eurisotop. The RAFT agent (4-cyano-4-(2-phenylethanesulfanylthiocarbonyl)-

Scheme 1. Schematic representation of the synthesis of the monomers and block copolymers.

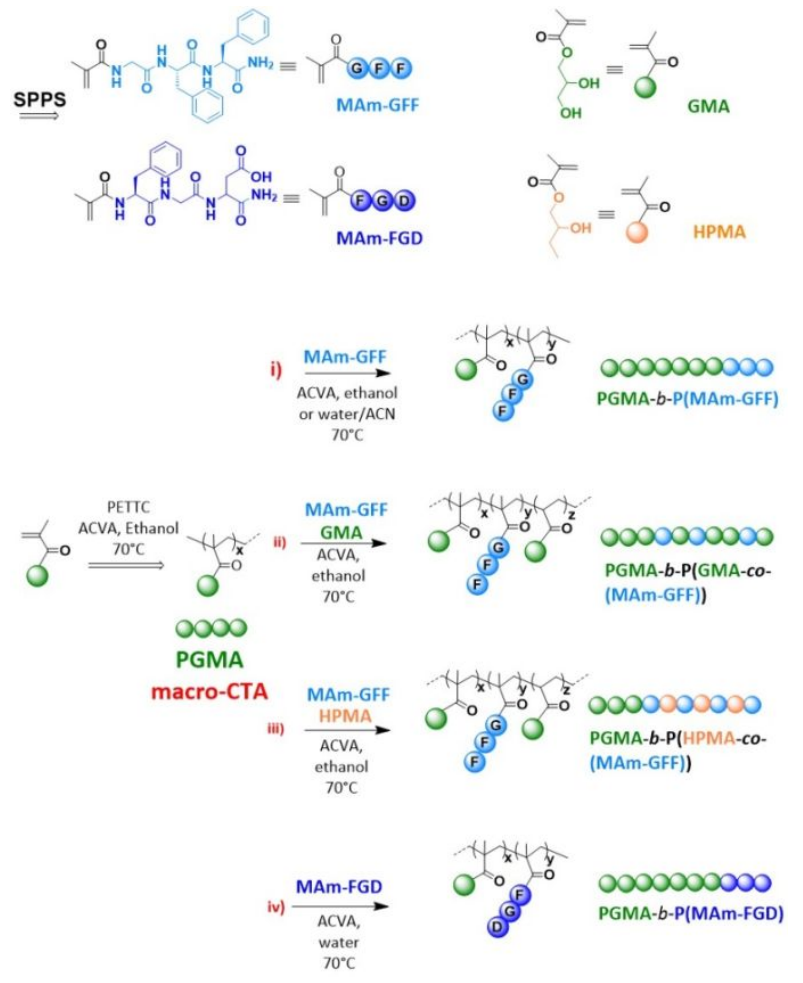

sulfanylpentanoic acid) (PETTC) and the peptide monomer MAmGFF was prepared according to our previous report. ${ }^{46}$

Synthesis of methacrylamide-functionalized peptide monomer MAm-FGD

MAm-FGD was synthesized on the resin using the same protocol employed to make MAm-GFF in our previous report ${ }^{46}$ but with Fmoc-Phe-OH, Fmoc-Gly-OH and Fmoc-Asp(But)-OH) as the amino acids. At the end, the tripeptide was cleaved from the resin with a $\mathrm{TFA} / \mathrm{TIS} / \mathrm{H}_{2} \mathrm{O}(95 / 2.5 / 2.5)$ mixture for $2 \mathrm{~h}$ at room temperature. It was recovered by precipitation in cold diethyl ether, taken up in water and freeze-dried. The obtained crude white powder was used for polymerisations without any further purification. Its purity and molecular structure were verified by LC-MS (Figure S2) and ${ }^{1} \mathrm{H}$ NMR spectroscopy (Figure S1). ${ }^{1} \mathrm{H}$ NMR in DMSO $\delta$ (ppm): $1.85(\mathrm{~s}, 3 \mathrm{H},-$ $\left.\mathrm{CH}_{3}\right)$; 2.66-2.73 (m, 2H, -CH-CH$\left.-\mathrm{Ph}\right) ; 2.90-3.10$ (dd, $2 \mathrm{H},-\mathrm{CH}_{2}-\mathrm{CH}_{2}-$ $\mathrm{COOH}$ ); 3.70 (m, 2H, -NH-CH $\left.{ }_{2} \mathrm{CO}-\right) 4.41\left(\mathrm{~m}, 2 \mathrm{H},-\mathrm{NH}-\mathrm{CHCO}-\mathrm{CH}_{2}-\right.$ ); $5.38(\mathrm{~s}, 1 \mathrm{H}$, vinyl); $5.71(\mathrm{~s}, 1 \mathrm{H}$, vinyl); 7.10-7.28 (m, $5 \mathrm{H}$, phenyl); 8.08-8.20 (m, 3H, - $\mathrm{NH}-)$.

\section{RAFT Homopolymerization of GMA}

A representative synthesis of the PGMA macromolecular chain transfer agents (mCTAs) proceeded as follows: a round bottom Schlenk flask equipped with a stirrer bar was charged with GMA (30 eq.), PETTC (1 eq.), ACVA initiator ( 0.1 eq.) and a volume of ethanol adjusted for the reaction to proceed at a solids content of $50 \%$ $w / w$. The flask was subsequently sealed with a rubber septum, placed in an ice-bath, degassed by bubbling nitrogen for $30 \mathrm{~min}$ and immersed in a preheated oil bath at $70^{\circ} \mathrm{C}$. After $2 \mathrm{~h}$, the polymerization was quenched by immersing the flask in ice-cold water and opening the reaction to air. GMA conversion was determined by ${ }^{1} \mathrm{H}$ NMR in methanol-d4, from the ratio of the integral of the residual vinyl ${ }^{1} \mathrm{H}$ signals at $5.65 \mathrm{ppm}(1 \mathrm{H})$ or $6.15 \mathrm{ppm}$ $(1 \mathrm{H})$ to the signals at $3.5-4.3(5 \mathrm{H})$. The mixture reaction was then dialyzed using a MWCO = 1kDa membrane against a 9/1 mixture of water and ethanol during two days and freeze-dried. The final product was a light yellow powder. The mean DP was determined by ${ }^{1} \mathrm{H}$ NMR and the molar mass distribution was determined using DMAC SEC. All the ${ }^{1} \mathrm{H}$ NMR spectra and SEC chromatograms of the PGMA mCTAs are provided in Figure S3-S6.

\section{Preparation of diblock PGMA $A_{x}-b-P(M A m-G F F)_{y}$ via RAFT-PISA using PGMA $_{x}$ as MCTA}

$\mathrm{PGMA}_{x}$ mCTA (1 eq.), MAm-GFF (y eq.), and ACVA (0.2 eq.) were charged into a $10-\mathrm{mL}$ glass vial and stirred with the chosen polymerization solvent. The vial was sealed, submerged in an icebath, degassed for 30 minutes and put into an oil-bath set previously at $70^{\circ} \mathrm{C}$. After $24 \mathrm{~h}$, reaction was cooled down, opened to the air and the MAm-GFF conversion was determined by ${ }^{1} \mathrm{H}$ NMR (comparison of the integral of the residual vinyl signals at $5.42(1 \mathrm{H})$ or $5.85(1 \mathrm{H})$ to that of the phenyl group at 7.2-7.4 $(10 \mathrm{H})$ ). Other aliquots were also taken for SEC, DLS and TEM analyses.

Preparation of diblock PGMA $_{18}-b-P\left((M A m-G F F)_{9}-\right.$ Co-GMA 48$)$ via RAFT-PISA using PGMA $_{18}$ as MCTA 
The procedure to prepare $\mathrm{PGMA}_{18}-\mathrm{b}-\mathrm{P}\left((\mathrm{MAm}-\mathrm{GFF})_{9}-\mathrm{Co}-\mathrm{GMA}_{48}\right)$ using $\mathrm{PGMA}_{18}$ as $\mathrm{mCTA}$ was as follows: PGMA $\mathrm{A}_{18} \mathrm{mCTA}$ (1 eq.), MAGFF (10 eq.) GMA (48 eq.) and ACVA (0.2 eq.) were stirred with pure ethanol into a $10-\mathrm{mL}$ glass vial. The vial was subsequently sealed with a rubber septum, submerged in an ice-bath, degassed by bubbling nitrogen for $30 \mathrm{~min}$ and immersed in a preheated oil bath at $70^{\circ} \mathrm{C}$. After $24 \mathrm{~h}$, the reaction was quenched by cooling and exposing to air. MAm-GFF conversion was determined as described above while GMA conversion was always $100 \%$ (no remaining GMAvinyl signals). Other aliquots were also taken for SEC, DLS and TEM analyses.

Preparation of diblock PGMA ${ }_{18}-b-P\left((M A m-G F F)_{9}-c o-H P M A_{61}\right)$ and PGMA $_{18}-b-\mathrm{P}\left((\mathrm{MAm}-\mathrm{GFF})_{19}-\mathrm{co}-\mathrm{HPMA}_{50}\right)$ via RAFT-PISA using $\mathrm{PGMA}_{18}$ as $\mathrm{MCTA}$

The procedures were as follow: PGMA 18 MCTA, MA-GFF, HPMA and ACVA at ratio $1: 10: 61: 0.2$ (to prepare $\mathrm{PGMA}_{18}-b-\mathrm{P}\left((\mathrm{MAm}-\mathrm{GFF})_{9-}\right.$ co-HPMA $\left.{ }_{61}\right)$ and $1: 20: 50: 0.2$ (to prepare PGMA $18-b-\mathrm{P}((\mathrm{MAm}-$ GFF) ${ }_{19}-$-Co-HPMA $\left.{ }_{50}\right)$ ) were stirred with ethanol into a $10-\mathrm{mL}$ glass vial. The vial was subsequently sealed with a rubber septum, submerged in an ice-bath, degassed by bubbling nitrogen for $\mathbf{3 0 ~ m i n}$ and immersed in a preheated oil bath at $70^{\circ} \mathrm{C}$. After $24 \mathrm{~h}$, the reaction was quenched by exposing to air. MAm-GFF conversion was determined as same as described above while HPMA conversion was always $100 \%$ (no remaining HPMA-vinyl signals). Other aliquots were also taken for SEC, DLS and TEM analyses.

Preparation of diblock PGMA $-b-P(M A m-F G D)_{y}$ via RAFT-PISA using PGMA ${ }_{x}$ as $M C T A$

The typical procedure of RAFT-PISA to prepare diblock PGMA $A_{x}-b$ $P(M A m-F G D)_{y}$ using $P G M A_{x}$ as $M C T A$ was carried out as described below. PGMA $\mathrm{mCTA}$ (1 eq.), MAm-FGD (y eq.), ACVA (0.2 eq.) and water (to reach $10 \% \mathrm{w} / \mathrm{w}$ of solids content) were charged into a 10 $\mathrm{mL}$ glass vial. The vial was sealed, degassed for 30 minutes and put into an oil-bath set previously at $70^{\circ} \mathrm{C}$. After $24 \mathrm{~h}$, reaction was cooled down, opened to the air and the MAm-FGD conversion was determined by ${ }^{1} \mathrm{H}$ NMR (comparison of its residual vinyl signals at $5.42(1 \mathrm{H})$ or $5.85(1 \mathrm{H})$ to the phenyl group at 7.2-7.4 $(5 \mathrm{H}))$. Other aliquots were also taken for SEC, DLS and TEM analyses.

\section{Characterization}

Liquid chromatography - mass spectrometry (LC-MS): LC-MS analyses were performed on Waters Alliance 2695 HPLC system, coupled to a Water Micromass ZQ spectrometer (electrospray ionization mode, ESI+). The peptide monomer MAm-GFF was dissolved in a minimum amount of DMF and diluted with acetonitrile/water $(50 / 50 \mathrm{v} / \mathrm{v})$ mixture containing $0.1 \%$ TFA. UV detection was performed at $214 \mathrm{~nm}$.

Proton nuclear magnetic resonance spectroscopy ( ${ }^{1} \mathbf{H}$ NMR): ${ }^{1} \mathrm{H}$ NMR spectra were recorded on a $300 \mathrm{MHz}$ Bruker Avance-300 spectrometer, processed and analyzed with MestReNova 9.0.

Size exclusion Chromatography (SEC): Polymer molar mass distributions were analysed using GPC Varian 390-LC system with PL1113-6300 ResiPore $300 \times 7.5$ columns connected with 390LC PL0390-0601 refractive index detector (RI). The mobile phase was DMAc with $0.1 \% \mathrm{w} / \mathrm{w} \mathrm{LiBr}$ adjusted at a flow rate of $1 \mathrm{~mL} \mathrm{~min}^{-1}$ while the columns were thermostated at $70^{\circ} \mathrm{C}$. The calibration was done with near-monodisperse Poly(methyl methacrylate) (PMMA) standards ranging from 550 to $1568000 \mathrm{~g} \mathrm{~mol}^{-1}$ (EasiVial-Agilent).

Dynamic light scattering (DLS): The hydrodynamic radii $\mathrm{RH}$ were analysed by dynamic light scattering at $90^{\circ}$ using Litesizer TM 500 Anton Paar. All measurements were performed at $20^{\circ} \mathrm{C}$ and with samples diluted to $0.1 \% \mathrm{w} / \mathrm{w}$.

Transmission Electron Microscopy (TEM): TEM images were acquired using either JEOL 1200 EXII-120 kV or JEOL 1400 P+ - 120 $\mathrm{kV}$. To prepare the TEM grid, $10 \mu \mathrm{L}$ of 100 -fold diluted sample from PISA suspension $(0.1 \% \mathrm{w} / \mathrm{w})$ was deposited onto the grid for $60 \mathrm{~s}$ and then blotted with filter paper to remove excess solution. Afterward, the sample-loaded grid was stained with $7 \mu \mathrm{L}$ of $1 \%$ ammonium molybdate solution for $20 \mathrm{~s}$ and also removed the excess stain with filter paper. The grid was allowed to dry under the hood for 5 minutes.

\section{Results and discussion}

\section{PGMA macromolecular chain transfer agents (PGMA mCTAs)}

The homopolymerizations of GMA were performed in ethanol under solution polymerization conditions. Although almost full conversion could be reached in $5 \mathrm{~h}$ as shown in previous studies, ${ }^{47}$ in this work, the polymerizations of GMA were stopped at about $60 \%$ conversion to ensure good end-group fidelity. The DP of the resulting PGMA mCTAs $(18,40$ and 83 for mCTAs 1, 2, and $\mathbf{3}$ respectively, Figure S3-5) were determined by ${ }^{1} \mathrm{H}$ NMR using the integrals of the signals of the backbone of PGMA (0.8-2 ppm, 5H) and of those of the PETTC end-group (7.2-7.4 ppm, 5H). All three mCTAs had narrow

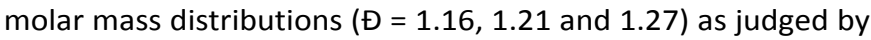
SEC in DMAc. SEC traces of these PGMA mCTAs are shown in Figure $\mathrm{S} 6$

PISA using the GFF-functionalized methacrylamide (MAmGFF)

The polymerizations of MAm-GFF using PGMA mCTAs to prepare self-assembled structures with $\mathrm{P}(\mathrm{MAm}-\mathrm{GFF})$ as coreforming block were performed in different media containing organic solvents since MAm-GFF is only sparingly soluble in pure water. Common good solvents for hydrophobic peptides are DMF, DMSO, acetonitrile and ethanol. DMF and DMSO could not be used here, as they are both good solvent for $\mathrm{P}(\mathrm{MAm}-\mathrm{GFF})$. Direct visual observation suggested that in ethanol, MAm-GFF was soluble up to $0.4 \% \mathrm{w} / \mathrm{w}$ at ambient temperature (ca. $20^{\circ} \mathrm{C}$ ) and up to $5 \% \mathrm{w} / \mathrm{w}$ at $70^{\circ} \mathrm{C}$. At higher concentrations $(7 \%-10 \% \mathrm{w} / \mathrm{w})$, it formed emulsion at both 20 and $70^{\circ} \mathrm{C}$. Furthermore, a mixture of water/acetonitrile was also chosen to study as the reaction medium. It was found that in water/acetonitrile $1 / 2 \mathrm{v} / \mathrm{v}$ mixture, MAm-GFF is dispersed up to $10 \% \mathrm{w} / \mathrm{w}$ at both $20^{\circ} \mathrm{C}$ and $70^{\circ} \mathrm{C}$, whereas in water/acetonitrile $1 / 1 \mathrm{v} / \mathrm{v}$ mixture, a $10 \% \mathrm{w} / \mathrm{w}$ MAm-GFF formed an emulsion at $20^{\circ} \mathrm{C}$ and a solution at $70^{\circ} \mathrm{C}$. TEM images of MAm-GFF-derived structures prepared in the above media at low concentration $(0.1 \% \mathrm{w} / \mathrm{w})$ are presented in Figure 1. 


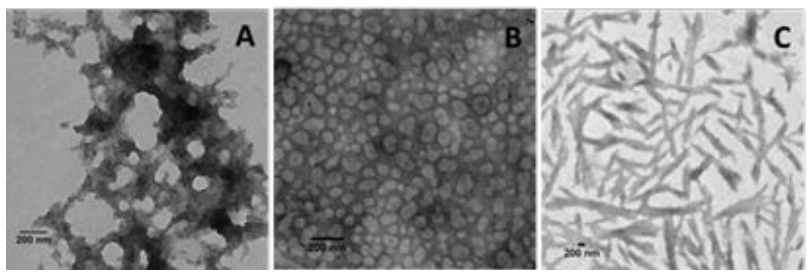

Figure 1. Representative TEM images of MAm-GFF-derived structures prepared from solutions at $c=0.1 \% \mathrm{w} / \mathrm{w}$ in: (A) water/acetonitrile $1 / 2 \mathrm{v} / \mathrm{v}$; (B) water/acetonitrile $1 / 1 \mathrm{v} / \mathrm{v}$ and (C) ethanol.

In the water/acetonitrile $1 / 2 \mathrm{v} / \mathrm{v}$ mixture, only ill-defined aggregates were observed (Figure $1 \mathrm{~A}$ ), suggesting that MAmGFF was completely solubilized. However, in mixture of water/acetonitrile $1 / 1 \mathrm{v} / \mathrm{v}$ or in ethanol, MAm-GFF selfassembled into relatively well-defined vesicular morphologies, (Figure 1B) and bundles of short fibers (Figure 1C). As discussed already in our previous work, ${ }^{46}$ the self-assembly of MAm-GFF is attributed to the combination of hydrogen bonding and aromatic $\pi$-stacking interactions between the FF moieties. The final morphologies thus are not only determined by MAm-GFF molecular structure but also by the solvent quality (polarity and hydrogen bonding properties). This was indeed illustrated here: changing the solvent from ethanol to water/acetonitrile $1 / 1 \mathrm{v} / \mathrm{v}$ mixture provides two types of distinct structures: fibres and vesicles.

These preliminary results on the solution properties of MAmGFF allowed its use in PISA formulation as the core-forming building block (scheme 1).

\section{PISA in ethanol}

Solids content effect: A series of polymerisation carried out in ethanol using mCTA 1 (PGMA $\left.{ }_{18}\right)$ : an initial ratio of 1: MAm-

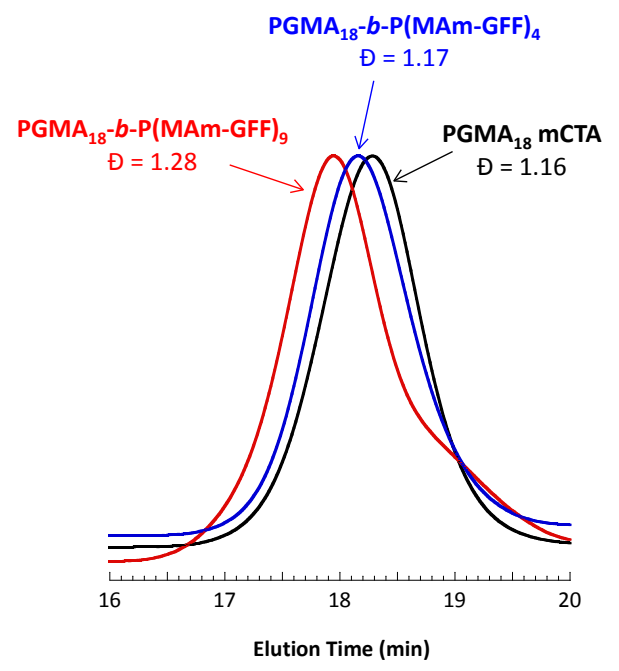

Figure 2. DMAC SEC chromatograms (refractive index detector) for mCTA $1\left(\mathrm{PGMA}_{18}\right)$ and the diblock copolymers $\mathrm{PGMA}_{18}-b$-P(MAm-GFF $)_{4}$ and $\mathrm{PGMA}_{18}-b-\mathrm{P}(\mathrm{MAm}-\mathrm{GFF})_{9}$ prepared via RAFT-mediated PISA at $70^{\circ} \mathrm{C}$ in ethanol at $11.2 \%$ $\mathrm{w} / \mathrm{w}$ and $12.5 \% \mathrm{w} / \mathrm{w}$ respectively.
GFF: ACVA of 1: 5: 0.2 , for $24 \mathrm{~h}$ at $70{ }^{\circ} \mathrm{C}$, at various solids content was performed. At $5 \% \mathrm{w} / \mathrm{w}$, the reaction proceeded under dispersion polymerization, however above $10 \% \mathrm{w} / \mathrm{w}$, the reaction became an emulsion polymerization. Surprisingly, only $45 \%$ MAm-GFF conversion could be attained at $5 \% \mathrm{w} / \mathrm{w}$ solids whereas at $11.2 \% \mathrm{w} / \mathrm{w}$ solids, MAm-GFF conversion reached $87 \%$. This trend was confirmed by a third experiment carried out at $12.5 \% \mathrm{w} / \mathrm{w}$ solids (targeting a DP of P(MAm-GFF) of 10) which reached $92 \%$ MAm-GFF conversion. The DMAc SEC traces (Figure 2 ) of the resulting $\mathrm{PGMA}_{18}-b-\mathrm{P}(\mathrm{MAm}-\mathrm{GFF})_{\mathrm{x}}$ diblock copolymers confirmed the relative good control of the RAFT polymerizations. However, a significant shoulder corresponding to the $\mathrm{MCTA}$ can be seen on the trace of the $\mathrm{PGMA}_{18}-b$-P(MAm-GFF) $)_{9}$ block copolymer, suggesting a suboptimal blocking efficiency.

In all cases, at $70^{\circ} \mathrm{C}$, the final reaction mixtures were turbid yellow suspensions. However, upon cooling, both suspensions were unstable. They became more turbid and yellow solids were observed on the wall of the vial at ambient temperature, even under continuous stirring, as shown in Figure S7. However, after dilution (100-fold) of the suspensions at $70{ }^{\circ} \mathrm{C}$ for TEM and DLS analyses, the samples remained stable at $20^{\circ} \mathrm{C}$. TEM images of the $\mathrm{PGMA}_{18}-b-\mathrm{P}(\mathrm{MAm}-\mathrm{GFF})_{4}$ diblock copolymer revealed the formation of flake-like objects about $50 \mathrm{~nm}$ wide and $100-200 \mathrm{~nm}$ long. In comparison, the PGMA ${ }_{18^{-}}$ $b$-P(MAm-GFF $)_{9}$ diblock copolymer formed micrometric branched bundles of fibers (Figure 3). In agreement with TEM results, DLS experiments indicated the presence of nanoobjects in $\mathrm{PGMA}_{18}-b-\mathrm{P}(\mathrm{MAm}-\mathrm{GFF})_{4}$ suspension with narrow size distribution (PDI = 0.187). Meanwhile, the DLS histogram of $\mathrm{PGMA}_{18}-b-\mathrm{P}(\mathrm{MAm}-\mathrm{GFF})_{9}$ showed the existence of large
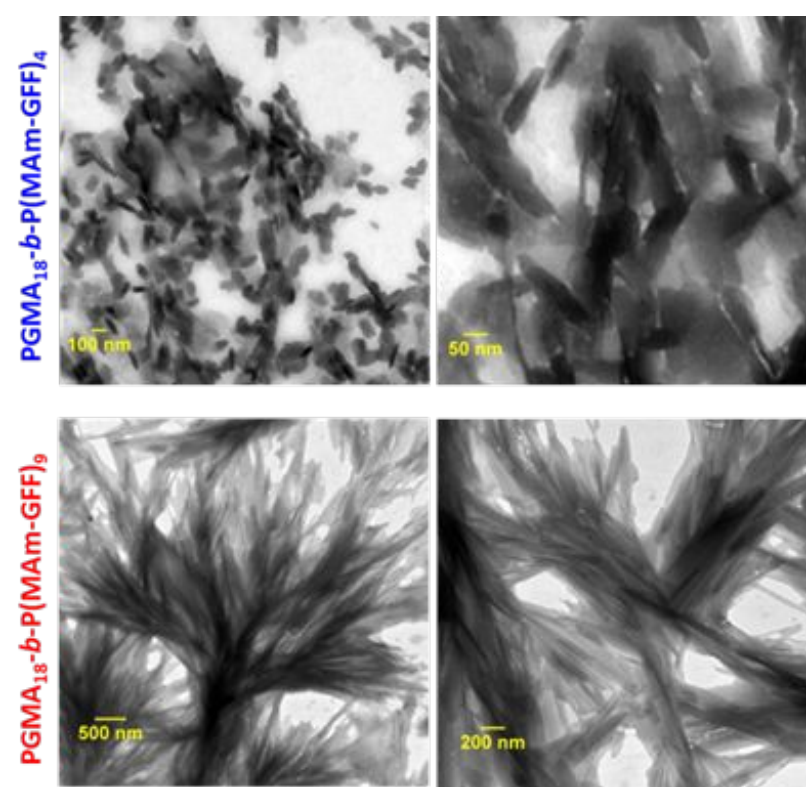

Figure 3. Representative TEM images at different magnification of the $\mathrm{PGMA}_{18}-b$-P(MAm-GFF) 4 (top row) and $\mathrm{PGMA}_{18}-b-\mathrm{P}(\mathrm{MAm}-\mathrm{GFF})_{9}$ (bottom row) diblock copolymers morphologies prepared by RAFT-PISA in ethanol at $11.2 \%$ and $12.5 \%$ solids content respectively. Samples were diluted $100-$ fold at $70^{\circ} \mathrm{C}$. 
structures at the micrometric scale. The size distribution in this case was broad, probably due to its highly anisotropic morphology as seen with TEM. DLS data are presented in Figure S8. The significant change in both size and shape between the two diblocks (PGMA $18-b-\mathrm{P}(\mathrm{MAm}-\mathrm{GFF})_{4}$ and $\mathrm{PGMA}_{18}-b$-P(MAm-GFF $\left.)_{9}\right)$ indicated that the length of the hydrophobic SAP block $P(M A m-G F F)$ effectively determines the final morphology of the PGMA- $b$-P(MAm-GFF) block copolymer. This result confirms the interplay and synergy between SAP and PISA in the formation of these morphologies.

\section{Effect of the mCTA length}

To overcome the instability, observed at $20^{\circ} \mathrm{C}$ for the previous diblock copolymer morphologies, stabilized by a relatively short PGMA $_{18}$, longer hydrophilic mCTAs: PGMA 40 (2) and PGMA ${ }_{83}$ (3) were used. All the PISA formulations were carried out at $12 \% \mathrm{w} / \mathrm{w}$ solids in ethanol. The polymerization led to yellow turbid suspensions after $24 \mathrm{~h}$. In these polymerizations, MAm-GFF conversions reached $90 \%$ or higher as judged by ${ }^{1} \mathrm{HNMR}$ and SEC analyses. However, the resulting diblock copolymers (PGMA ${ }_{40}-b$ $\mathrm{P}(\mathrm{MAm}-\mathrm{GFF})_{8}, \quad \mathrm{PGMA}_{83}-b-\mathrm{P}(\mathrm{MAm}-\mathrm{GFF})_{10}$ and $\mathrm{PGMA}_{83}-b-\mathrm{P}(\mathrm{MAm}-$ GFF $)_{6}$ ) suspensions again lost their colloidal stability upon cooling from $70^{\circ} \mathrm{C}$ to $20^{\circ} \mathrm{C}$. Increasing the length of the PGMA block did not improve the stability of PGMA- $b$-P(MAm-GFF) self-assembled objects. Here, the balance between the hydrophobic and hydrophilic parts in the PGMA- $b$-P(MAm-GFF) system was not the dominant element in the self-assembly in contrast to the case of PGMA- $b$-PHPMA which have been thoroughly described. ${ }^{48}$ The morphologies observed here were likely more affected by the selfassembling properties of the polypeptide part.

The diblock copolymer morphologies were observed by TEM using 100 -fold diluted samples. The dilution was carried out at $70^{\circ} \mathrm{C}$. Welldefined morphologies were observed for all PISA formulations as shown in Figure 4. In all cases, despite the composition difference, the self-assembled morphologies were large (several $\mu \mathrm{m}$ ) dendritic structures similar to the structures observed for $\mathbf{P G M A}_{\mathbf{1 8}} \mathbf{b} \boldsymbol{b}$ P(MAm-GFF), and composed of fibrous elements (Figure 4). These fibrous substructures were better defined for the diblocks prepared from the longer $\mathrm{PGMA}_{83} \mathrm{mCTA}$. Increasing the length of the $P(M A m-G F F)$ block from 6 to 10 for these $\mathrm{PGMA}_{83}$-derived block copolymers led to even better defined fibrous substructures (Figure 4). When $\mathrm{PGMA}_{40}$ was used as the stabilizing block, these substructures lost much of their fiber-like aspect.

\section{Effect of the composition of the core-forming block}

The effect of the composition of the solvophobic block was also examined by replacing the $P(M A m-G F F)$ segment by a copolymer of HPMA (or GMA) and MAm-GFF. GMA and HPMA are highly soluble in ethanol. Three PISA formulations based on MCTA 1 were examined: 1: GMA: MAm-GFF = 1: 48: 10, 1: HPMA: MAm-GFF = 1: 61: 10, and 1: HPMA: MAm-GFF = 1: 50: 20. The addition of GMA or HPMA increased the solubility of MAm-GFF in the reaction medium, and thus the PISA could be carried out at higher solids contents $(15 \% \mathrm{w} / \mathrm{w})$ which led to higher monomer conversions. The SEC chromatograms of the resulting diblock copolymers shown in Figure

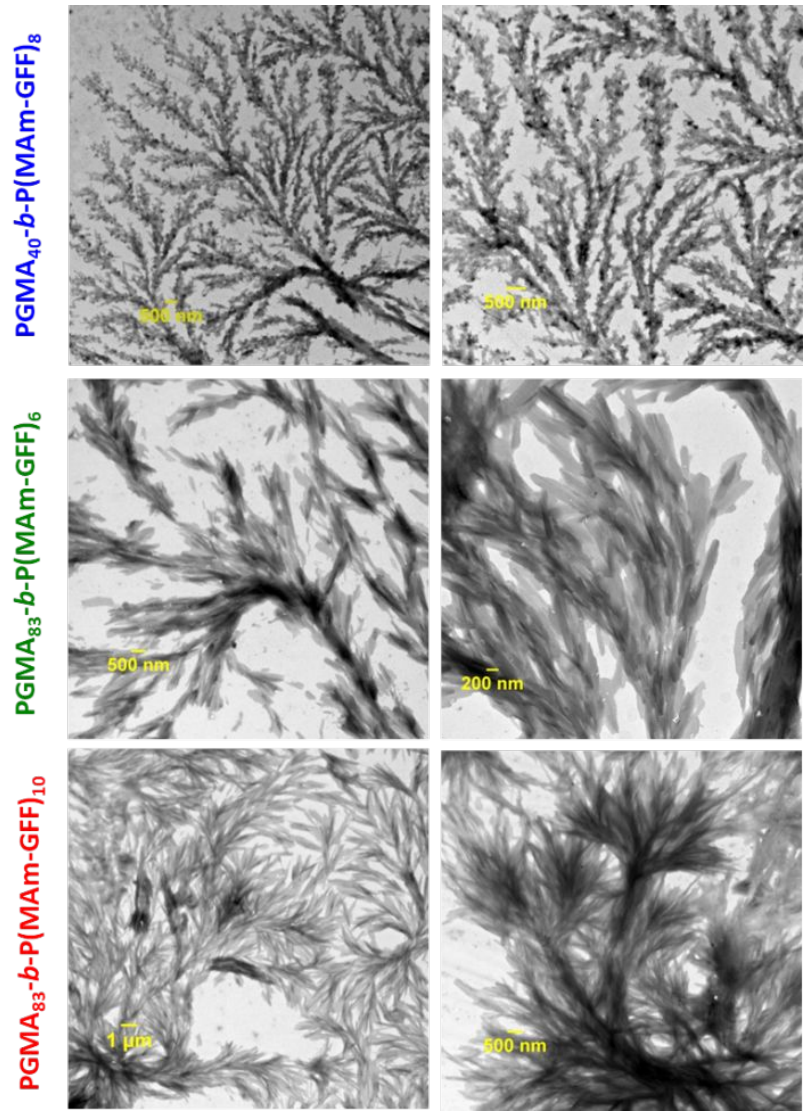

Figure 4. Representative TEM images of the $P G M A_{40}-b-P(M A m-$ GFF $)_{8}, \quad \mathrm{PGMA}_{83}-b-\mathrm{P}(\mathrm{MAm}-\mathrm{GFF})_{6}$ and $\mathrm{PGMA}_{83}-b-\mathrm{P}(\mathrm{MAm}-\mathrm{GFF})_{10}$ diblock copolymers morphologies prepared RAFT PISA in emulsion in ethanol at $12 \%$ solids. The samples were diluted to $0.1 \% \mathrm{w} / \mathrm{w}$ at $70^{\circ} \mathrm{C}$.

5 suggest that the PISA copolymerizations proceeded with relatively good control (the trace are monomodal and shifted towards higher

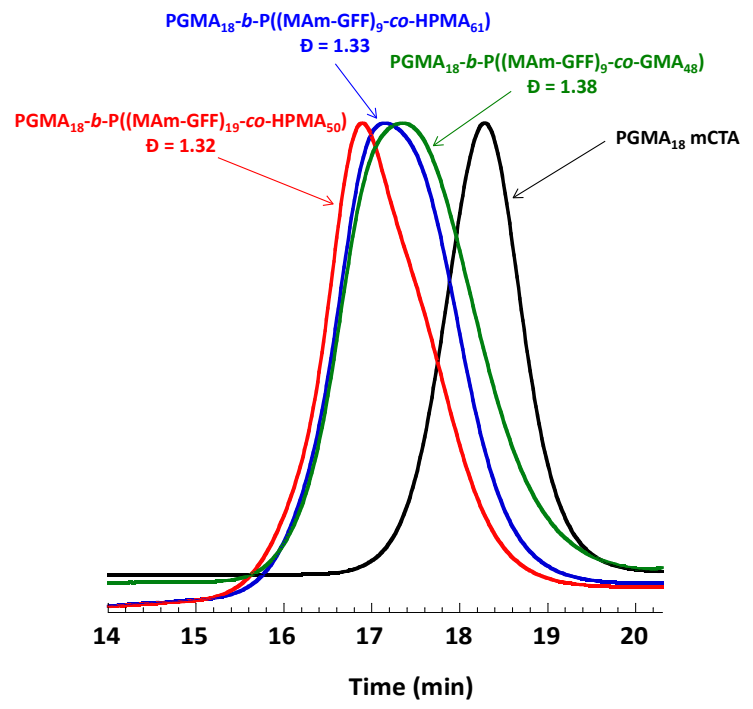

Figure 5. DMAC SEC chromatograms (refractive index detector) for mCTA 1 (PGMA 18 ) and the three diblock copolymers prepared by RAFT PISA in emulsion in ethanol. 
molar masses). However, these chromatograms were also slightly broad suggesting a subpar blocking efficiency.

As in the case of the previous formulations described above, the suspension of $\mathrm{PGMA}_{18}-\mathrm{b}-\mathrm{P}\left((\mathrm{MAm}-\mathrm{GFF})_{9}-\mathrm{Co}-\mathrm{GMA}_{48}\right)$ diblock copolymer was turbid and stable at $70^{\circ} \mathrm{C}$ but rapidly lost colloidal stability in a few minutes after cooling down (Figure S9). TEM images of the sample diluted at $70^{\circ} \mathrm{C}$ showed large clusters of fibrous structures. In contrast, the $\mathrm{PGMA}_{18}-b-\mathrm{P}\left((\mathrm{MAm}-\mathrm{GFF})_{9}-\mathrm{CO}-\right.$ $\left.\mathrm{HPMA}_{61}\right)$ and $\mathrm{PGMA}_{18}-b-\mathrm{P}\left((\mathrm{MAm}-\mathrm{GFF})_{19}-\mathrm{CO}-\mathrm{HPMA}_{50}\right)$ diblock copolymers suspensions were colloidally stable at both $70^{\circ} \mathrm{C}$ and $20^{\circ} \mathrm{C}$. The TEM images of these morphologies (samples prepared at $\left.20^{\circ} \mathrm{C}\right)$ show that $\mathrm{PGMA}_{18}-b-\mathrm{P}\left((\mathrm{MAm}-\mathrm{GFF})_{19}-\mathrm{Co}-\mathrm{HPMA}_{50}\right)$ selfassembled into vesicles while $\mathrm{PGMA}_{18}-b-\mathrm{P}\left((\mathrm{MA}-\mathrm{GFF})_{9}-\mathrm{Co}-\mathrm{HPMA}_{61}\right)$ self-assembled into a mixture of short worms and vesicles (Figure 6). It is worth noticing here that these vesicles are undoubtedly the results of the self-assembling properties of MAm-GFF since PGMA$b$-PHPMA block copolymers are completely soluble in ethanol.

\section{Solvent effect}

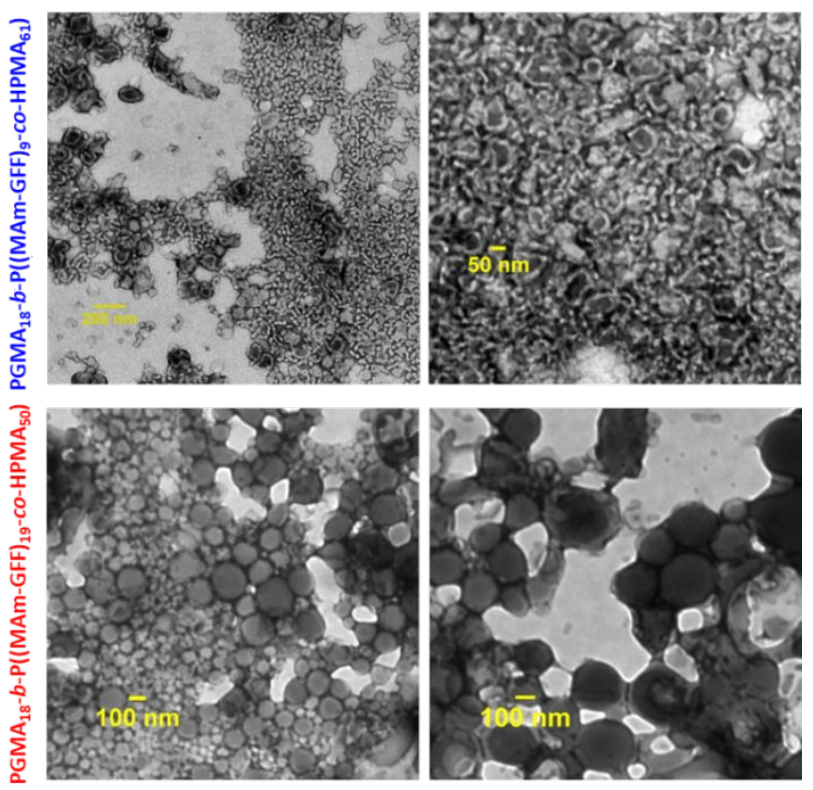

Figure 6. Representative TEM images of the $\mathrm{PGMA}_{18}-b-\mathrm{P}((\mathrm{MAm}$ GFF) ${ }_{9}$-co-HPMA ${ }_{61}$ ) diblock copolymer morphology (top row) and of the $\mathrm{PGMA}_{18}-b$-P((MAm-GFF) ${ }_{19}$-Co-HPMA $\left.{ }_{50}\right)$ diblock copolymer morphology (bottom row) prepared by RAFT PISA in dispersion in ethanol at $15 \% \mathrm{w} / \mathrm{w}$ solids. The samples were diluted to $0.15 \%$ $\mathrm{w} / \mathrm{w}$ at $20^{\circ} \mathrm{C}$.

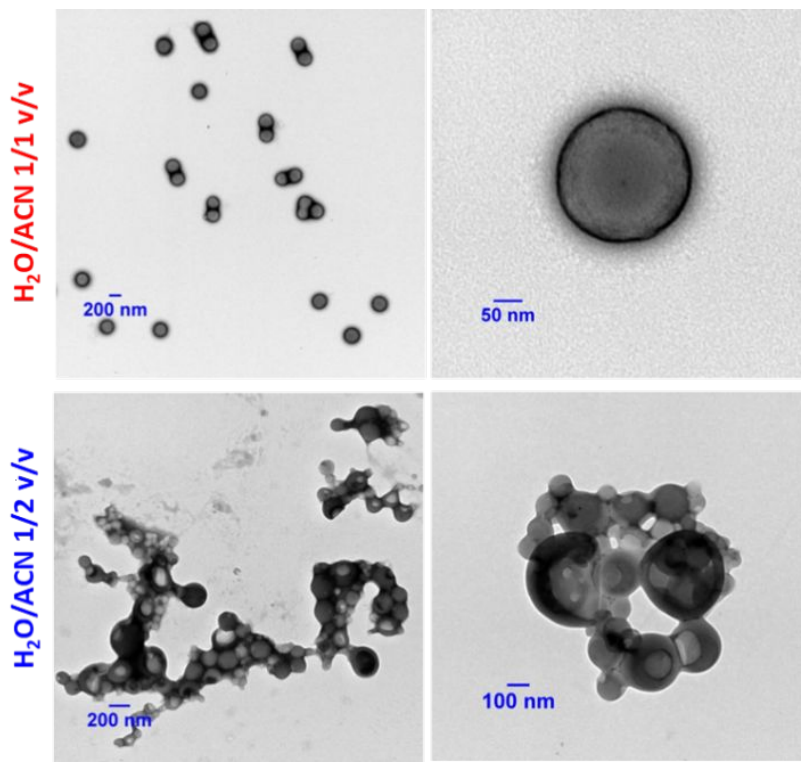

Figure 7. Representative TEM images of the $\mathrm{PGMA}_{40}-b-\mathrm{P}(\mathrm{MAm}$ GFF) ${ }_{15}$ diblock copolymer morphology in $1 / 1 \mathrm{v} / \mathrm{v}$ (top row) and $(1 / 2$ $\mathrm{v} / \mathrm{v}$ ) (bottom row) water/acetonitrile mixtures prepared by RAFT PISA in dispersion at $10 \% \mathrm{w} / \mathrm{w}$ solids at $70^{\circ} \mathrm{C}$. The samples were diluted to $0.1 \% \mathrm{w} / \mathrm{w}$.

The effect of the solvent on the PISA of PGMA-b-P(MAm-GFF) diblock copolymer was investigated, and ethanol was replaced by water/acetonitrile mixtures. The following PISA formulation based on mCTA 2 was examined: 2: MAm-GFF: ACVA = 1: 20: 0.2 in 1/1 v/v and $1 / 2 \mathrm{v} / \mathrm{v}$ water/acetonitrile mixtures. The polymerizations were carried out at $10 \mathrm{w} / \mathrm{w}$ solids under RAFT dispersion polymerization conditions at $70^{\circ} \mathrm{C}$. The MAm-GFF conversions reached $69 \%$ and $72 \%$ in $1 / 1 \mathrm{v} / \mathrm{v}$ and $1 / 2 \mathrm{v} / \mathrm{v}$ water/acetonitrile mixtures respectively. Formation of the diblock copolymers via successful chain extension of the macro-CTA with P(MAm-GFF) was confirmed by SEC DMAc as shown in Figure S10. The resulting diblock copolymer morphologies were well-dispersed, giving rather clear colloidal suspensions that remained colloidaly stable even upon cooling to $20^{\circ} \mathrm{C}$. TEM images (Figure 7) showed that PGMA $40^{-} b$ (MAm-GFF) ${ }_{15}$ formed monodisperse $220 \mathrm{~nm}$ spherical particles in water/acetonitrile $1 / 1 \mathrm{v} / \mathrm{v}$. In water/acetonitrile $1 / 2 \mathrm{v} / \mathrm{v}$ the PISA of $\mathrm{PGMA}_{40}-b$-(MAm-GFF $)_{15}$ led to polydisperse vesicles with diameters ranging between 50 and $400 \mathrm{~nm}$. In contrast to the PISA experiments carried out in ethanol which resulted in unstable dispersions and fibrous structures, no fibrous structures were observed for PGMA- $b$-P(MAm-GFF) in the two water/acetonitrile mixtures examined. It is however important to note that the diblock copolymers prepared in ethanol and in water/acetonitrile were not strictly identical. So the difference in their morphologies may not be ascribed only to the effect of solvent.

\section{PISA using GFD-functionalized methacrylamide (MAm-FGD)}

In order to perform PISA under aqueous dispersion conditions, a new peptide-functionalized methacrylamide, MAm-FGD, was designed. This monomer, reported for its self-assembling properties, similar to MAm-GFF contains a phenylalanine residue, however it is less hydrophobic as it also contains a polar aspartic 

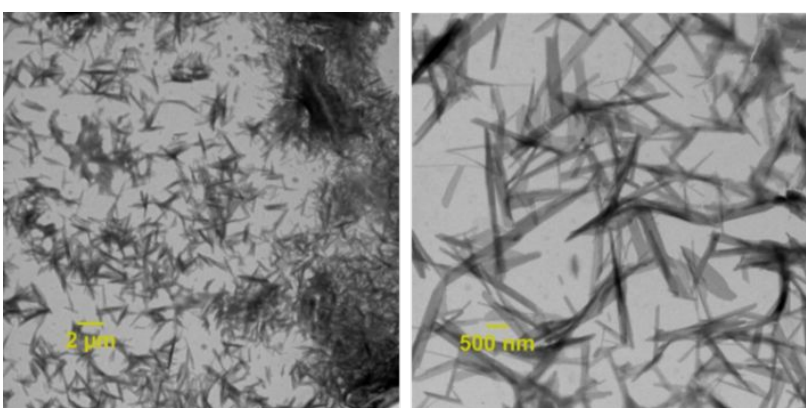

Figure 8. Representative TEM images of self-assembled structures of MAm-FGD in water at $0.1 \% \mathrm{w} / \mathrm{w}$.

acid unit instead of a second phenylalanine moiety. Indeed, MAmFGD was soluble in water up to $10 \% \mathrm{w} / \mathrm{w}$. The TEM images (Figure 8) of the MAm-FGD aqueous solution at $0.1 \% \mathrm{w} / \mathrm{w}$ revealed the presence of long (several $\mu \mathrm{m}$ ) shard-like structures with width in the $100-200 \mathrm{~nm}$ range that sometimes aggregated into bundles. These TEM images confirmed that a single phenylalanine unit can also drive self-assembly and lead to the formation of fibrous structures, as demonstrated by Gazit et al. ${ }^{49}$
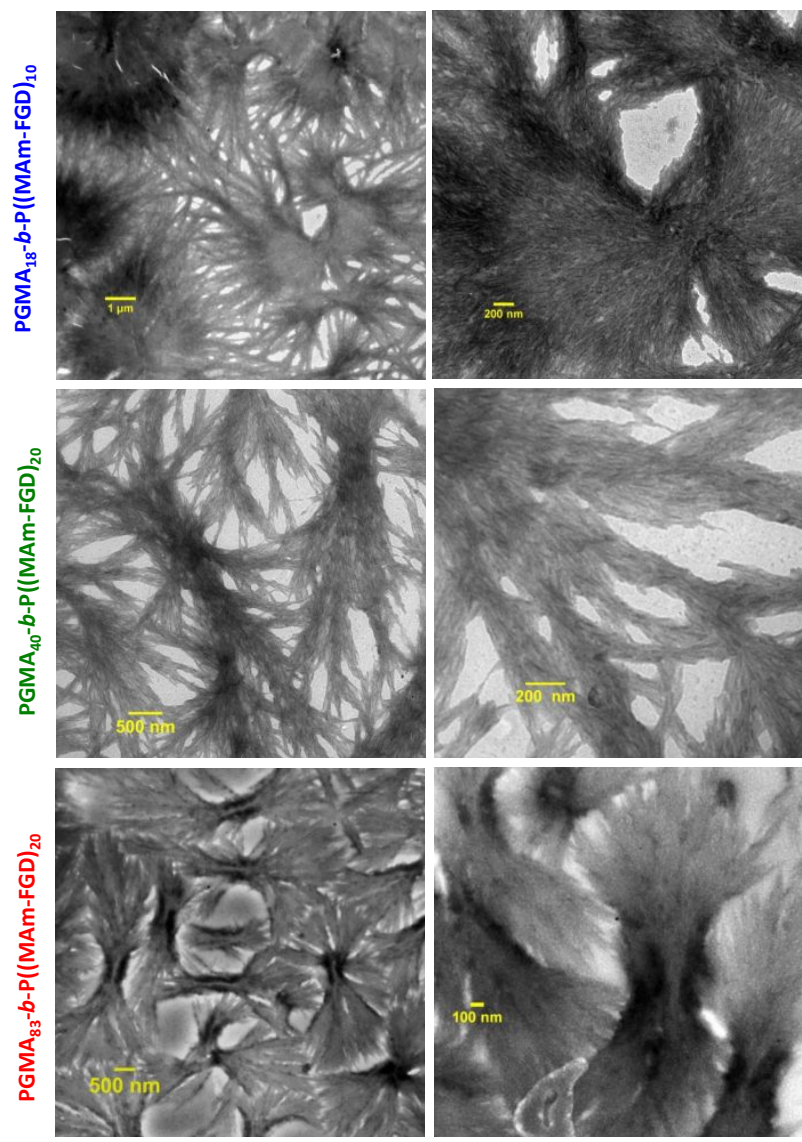

Figure 9. Representative TEM images at different magnification of the $\mathrm{PGMA}_{18}-b-\mathrm{P}(\mathrm{MAm}-\mathrm{FGD})_{10}$ (top row), $\mathrm{PGMA}_{40}-b-\mathrm{P}(\mathrm{MAm}-\mathrm{FGD})_{20}$, (medium row) and $\mathrm{PGMA}_{83}-b-$ $\mathrm{P}(\mathrm{MAm}-\mathrm{FGD})_{20}$ (bottom row) diblock copolymer morphologies prepared by RAFT PISA aqueous dispersion at $10 \% \mathrm{w} / \mathrm{w}$ solids. The samples were diluted to $0.1 \% \mathrm{w} / \mathrm{w}$.
Polymerizations of MAm-FGD were performed using mCTAs 1, 2 and 3 at $10 \% \mathrm{w} / \mathrm{w}$ solids in water. In all cases, 100\% MAm-FGD conversion were achieved and a yellow turbid suspension was obtained. Three diblock copolymers were thus prepared: $\mathbf{P G M A}_{\mathbf{1 8}} \mathbf{B}^{-}$ $b$-P(MAm-FGD) ${ }_{10}$, PGMA $_{40}-b$-P(MAm-FGD $)_{20}$ and PGMA P3- $^{-b}$ $\mathbf{P}(\mathbf{M A m}-\mathrm{FGD})_{\mathbf{2 0}}$. All three samples formed colloidally stable suspensions at both $70^{\circ} \mathrm{C}$ and $20^{\circ} \mathrm{C}$. TEM images of these suspensions revealed the formation of large dendritic and bow-tie shaped fibrous spherulitic structures (Figure 9). Although the overall shape is similar for all the compositions, indicating similar organization, a closer look at their internal structures reveals slight differences as seen in images at higher magnifications. From $\mathrm{PGMA}_{18}-b-\mathrm{P}(\mathrm{MAm}-\mathrm{FGD})_{10}, \quad \mathrm{PGMA}_{40}-b-\mathrm{P}(\mathrm{MAm}-\mathrm{FGD})_{20}$ to PGMA $_{\mathbf{8 3}}-\boldsymbol{b}$-P(MAm-FGD) $)_{20}$, it seems that the fibers become shorter and the structures tend to be less packed.

\section{Conclusions}

Nanostructures constituted of a solvophilic PGMA corona and peptide-containing solvophobic cores were successfully prepared via RAFT-mediated Polymerization-Induced-Selfassembly using SAP-functionalized methacrylamide. The selfassembly of these polymer-polypeptide formulations proved to be much more diverse compared to the polymeric nanoobjects reported in previous PISA works. PISA formulations based on PGMA- $b-\mathrm{P}$ (MAm-GFF) or PGMA- $b$-P(MAm-FGD) formed large spherulitic bundles of fibrous structures in ethanol and water respectively. In contrast, only spherical particles and vesicles were observed for PGMA- $b$-P(MAm-GFF) synthesized via PISA in dispersion in water/acetonitrile mixtures. As observed in our previous work ${ }^{46}$ the introduction of only few SAP residues was necessary to greatly influence the self-assembled morphology. This observation further strengthens our hypothesis that PISA and SAP motifs can synergistically contribute to the formation of nano- and micrometric morphologies.

\section{Conflicts of interest}

There are no conflicts to declare.

\section{Acknowledgements}

PDRA fellowship managed by the French national research agency (ANR): "investissement d'Avenir" LabEX CheMISyst, grant number ANR-10-LABX-05-01. The authors also thank CNRS for funding this work via the "Osez l'interdisciplinarité" programme awarded to MS.

\section{Notes and references}

1. J. Shu, B. Panganiban and T. Xu, Annual review of physical chemistry, 2013, 64, 631-657.

2. V. Mikhalevich, I. Craciun, M. Kyropoulou, C. G. Palivan and W. Meier, Biomacromolecules, 2017, 18, 3471-3480. 
3. E. Radvar and H. Azevedo, Macromolecular Bioscience, 2018, 19, 1800221.

4. N. Habibi, N. Kamaly, A. Memic and H. Shafiee, Nano Today, 2016, 11, 41-60.

5. D. Mandal, A. Shirazi and K. Parang, Organic \& biomolecular chemistry, 2014, 12, 3544-3561.

6. J. Ryu and C. Park, Biotechnology and bioengineering, 2010, 105, 221-230.

7. C. Görbitz, Chemical communications (Cambridge, England), 2006, 22, 2332-2334.

8. S. Marchesan, A. Vargiu and K. Styan, Molecules (Basel, Switzerland), 2015, 20, 19775-19788.

9. L. Adler-Abramovich, D. Aronov, P. Beker, M. Yevnin, S. Stempler, L. Buzhansky, G. Rosenman and E. Gazit, Nature nanotechnology, 2009, 4, 849-854.

10. M. Reches and E. Gazit, Nano Lett, 2004, 4, 581-585.

11. M. Reches and E. Gazit, Physical biology, 2006, 3, S10-19.

12. R. Huang, W. Qi, R. Su, J. Zhao and Z. He, Soft Matter, 2011, 7, 6418.

13. C. Guo, Y. Luo, Z. Ruhong and G. Wei, Nanoscale, 2014, 6, 2800-2811.

14. M. Reches and E. Gazit, Science (New York, N.Y.), 2003, 300, 625-627.

15. H. Arakawa, K. Takeda, S. Higashi, A. Shibata, Y. Kitamura and M. Ikeda, Polymer Journal, 2020, DOI: 10.1038/s41428-019-0301-5, 1-8.

16. S. Stupp, Nano letters, 2010, 10, 4783-4786.

17. J. Wang, K. Liu, R. Xing and X. Yan, Chemical Society reviews, 2016, 45, 5589-5604.

18. A. Mendes, E. Baran, R. L. Reis and H. Azevedo, Wiley interdisciplinary reviews. Nanomedicine and nanobiotechnology, 2013, 6, 582-612.

19. P. Makam and E. Gazit, Chemical Society Reviews, 2018, 47, 3406-3420.

S. Zhang, Nature biotechnology, 2003, 21, 1171-1178.

21. Z. Fan, L. Sun, Y. Huang, Y. Wang and M. Zhang, Nature Nanotechnology, 2016, 11, 388-394.

22. M. Şardan Ekiz, G. Cinar, M. Khalily and M. Guler, Nanotechnology, 2016, 27, 402002.

23. L. Adler-Abramovich, M. Reches, V. Sedman, S. Allen, S. Tendler and E. Gazit, Langmuir : the ACS journal of surfaces and colloids, 2006, 22, 1313-1320.

24. M. Lansalot and J. Rieger, Macromolecular Rapid Communications, 2019, 40, 1800885.

25. N. Penfold, J. Yeow, C. Boyer and S. Armes, ACS Macro Letters, 2019, 8, 1029-1054.

26. C. Ferguson, R. Hughes, B. Pham, B. Hawkett, R. Gilbert, A. Serelis and C. Such, Macromolecules, 2002, 35, 9243.

27. V. Cunningham, A. Alswieleh, K. Thompson, M. Williams, G. Leggett, S. Armes and O. Musa, Macromolecules, 2014, 47, 5613-5623.

28. M. Derry, L. Fielding and S. Armes, Polym. Chem., 2015, 6, 3054-3062.

29. M. Semsarilar, V. Ladmiral, A. Blanazs and S. P. Armes, Langmuir, 2012, 28, 914-922.

30.

A. Blanazs, J. Madsen, G. Battaglia, A. Ryan and S. Armes, Journal of the American Chemical Society, 2011, 133, 16581-16587.

31.

A. Blanazs, A. Ryan and S. Armes, Macromolecules, 2012, 45, 5099-5107.

32. P. Chambon, A. Blanazs, G. Battaglia and S. Armes, Macromolecules, 2012, 45, 5081-5090.
33.

34.

34.

M. Semsarilar, V. Ladmiral, A. Blanazs and S. P. Armes, Langmuir, 2013, 29, 7416-7424.

S. Boissé, J. Rieger, B. Khaled, A. Di-Cicco, P. Beaunier, M.$\mathrm{H}$. Li and B. Charleux, Chemical communications (Cambridge, England), 2010, 46, 1950-1952.

I. Chaduc, A. Crepet, O. Boyron, B. Charleux, F. D'Agosto and M. Lansalot, Macromolecules, 2013, 46, 6013-6023.

W. Zhang, F. D'Agosto, O. Boyron, J. Rieger and B. Charleux, Macromolecules, 2011, 44, 7584-7593.

I. Chaduc, W. Zhang, J. Rieger, M. Lansalot, F. D'Agosto and B. Charleux, Macromolecular rapid communications, 2011, 32, 1270-1276.

M. Derry, L. Fielding and S. Armes, Progress in Polymer Science, 2016, 52, 1-18.

M. Semsarilar, V. Ladmiral, A. Blanazs and S. Armes, Polym. Chem., 2014, 5, 3466-3475.

M. Semsarilar, N. Penfold, L. Jones and S. Armes, Polym. Chem., 2015, 6, 1751-1757. 1502-1509.

43. A. Lopez-Oliva, N. Warren, A. Rajkumar, O. Mykhaylyk, M. Derry, K. Doncom, M. Rymaruk and S. Armes, Macromolecules, 2015, 48, 150522153344002.

44. Q. Zhang and S. Zhu, ACS Macro Letters, 2015, 4, 755-758.

45. D. Zhou, R. Kuchel, S. Dong, F. Lucien, S. Perrier and P. Zetterlund, Macromolecular Rapid Communications, 2018, 40, 1800335.

46. T. P. T. Dao, L. Vezenkov, G. Subra, M. Amblard, M. In, J.-F. Le Meins, F. Aubrit, M.-A. Moradi, V. Ladmiral and M. Semsarilar, Macromolecules, Submitted.

47. V. Ladmiral, M. Semsarilar, I. Cantón and S. Armes, Journal of the American Chemical Society, 2013, 135, 1357413581.

48. N. Warren and S. Armes, Journal of the American Chemical Society, 2014, 136, 10174-10185.

49. L. Adler-Abramovich, L. Vaks, O. Carny, D. Trudler, A. Magno, A. Caflisch, D. Frenkel and E. Gazit, Nature chemical biology, 2012, 8, 701-706. 


\section{Nano-assemblies with Core-Forming Hydrophobic Polypeptide via Polymerization-Induced Self-Assembly (PISA)}

T. P. Tuyen Dao ${ }^{a, b, c}$, Lubomir Vezenkov ${ }^{c}$, Gilles Subrac, Vincent Ladmiral ${ }^{b}$, Mona Semsarilar ${ }^{a^{*}}$

a. Institut Européen des Membranes, IEM, Univ Montpellier, CNRS, ENSCM, Montpellier, France

b. Institut Charles Gerhardt Montpellier, ICGM, Univ Montpellier, CNRS, ENSCM, Montpellier, France

c. Institut des Biomolécules Max Mousseron, IBMM, Univ Montpellier, CNRS, ENSCM, Montpellier, France

\section{SUPPORTING INFORMATION}

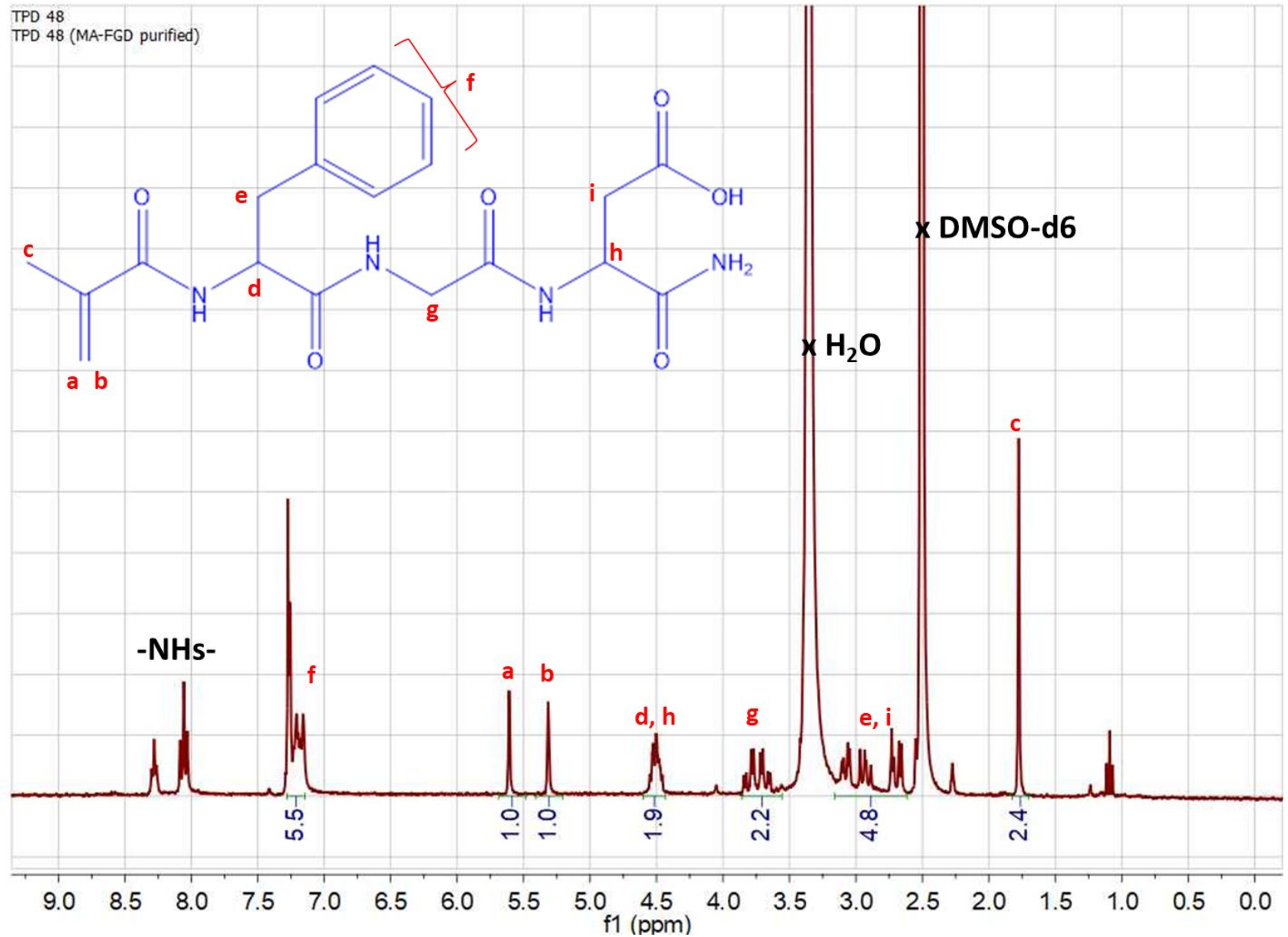

Figure S1. Chemical structure and ${ }^{1} \mathrm{H}$ NMR spectrum in DMSO-d6 of MAm-FGD

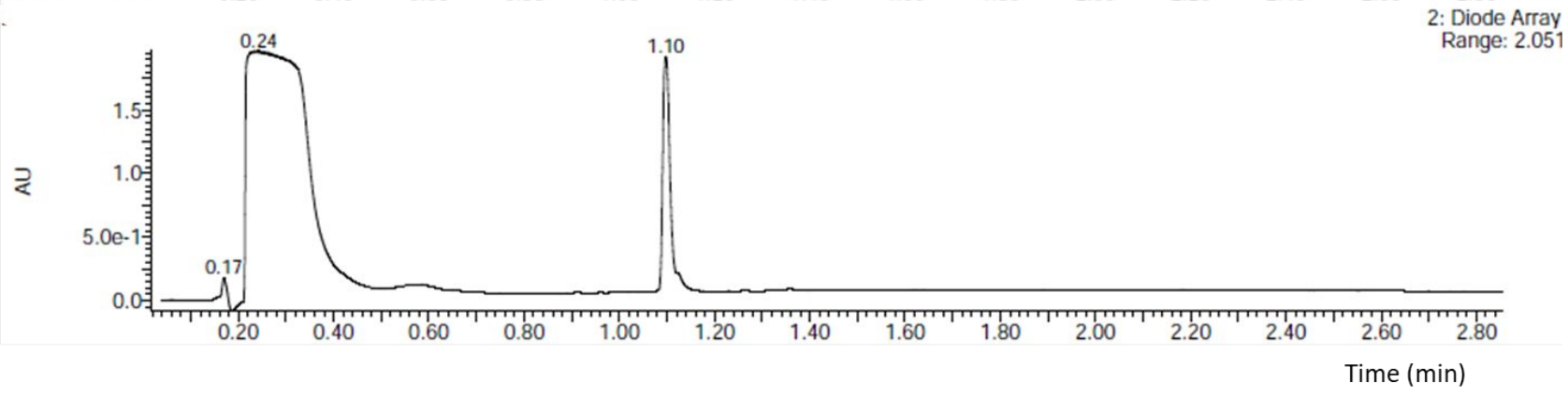




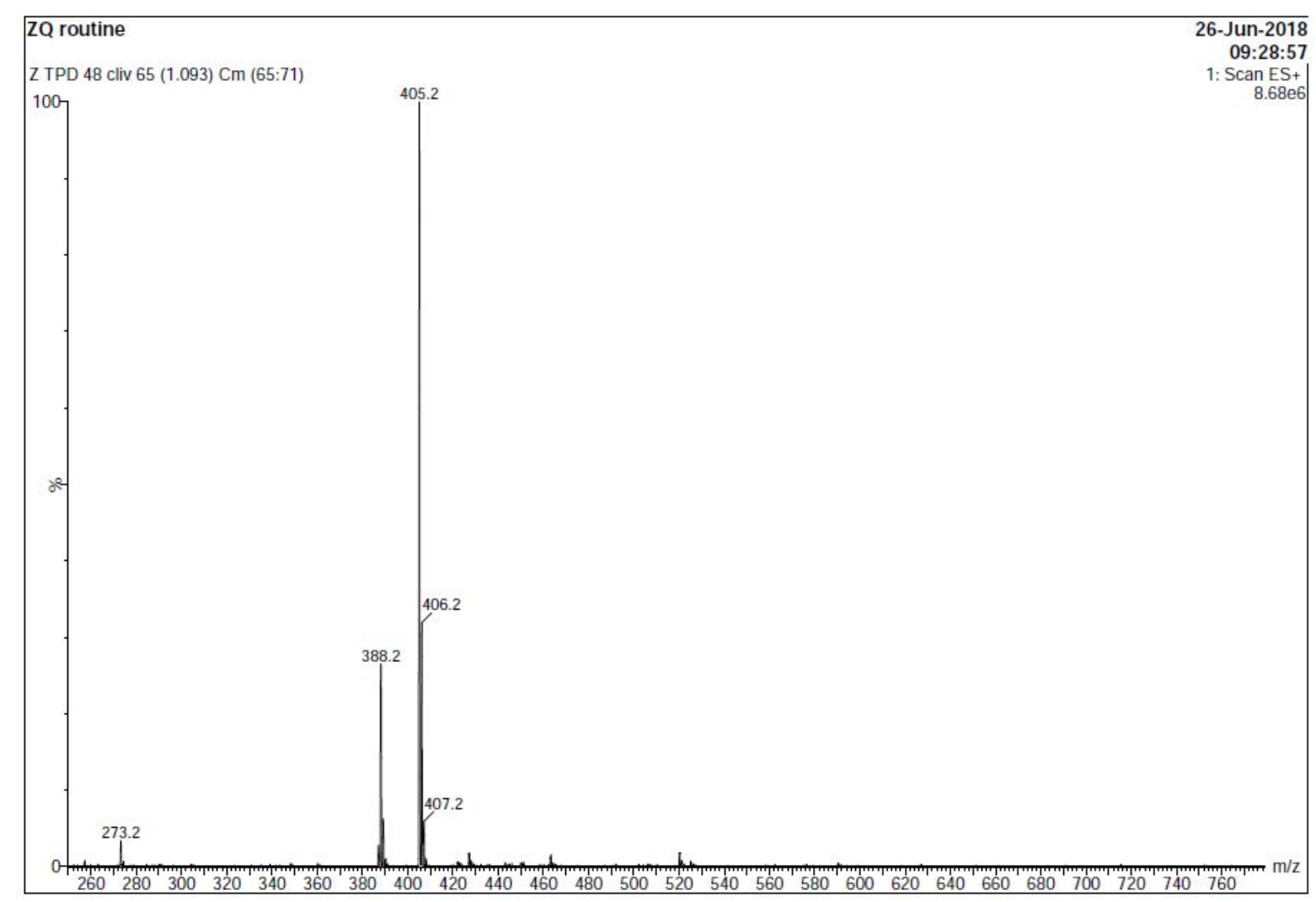

Figure S2. HPLC profiles and ESI-MS of MAm-FGD $\left(t_{R}=1.10 \mathrm{~min}, \mathrm{~m} / \mathrm{z} 405.2\left([\mathrm{M}+\mathrm{H}]^{+}\right)\right)$

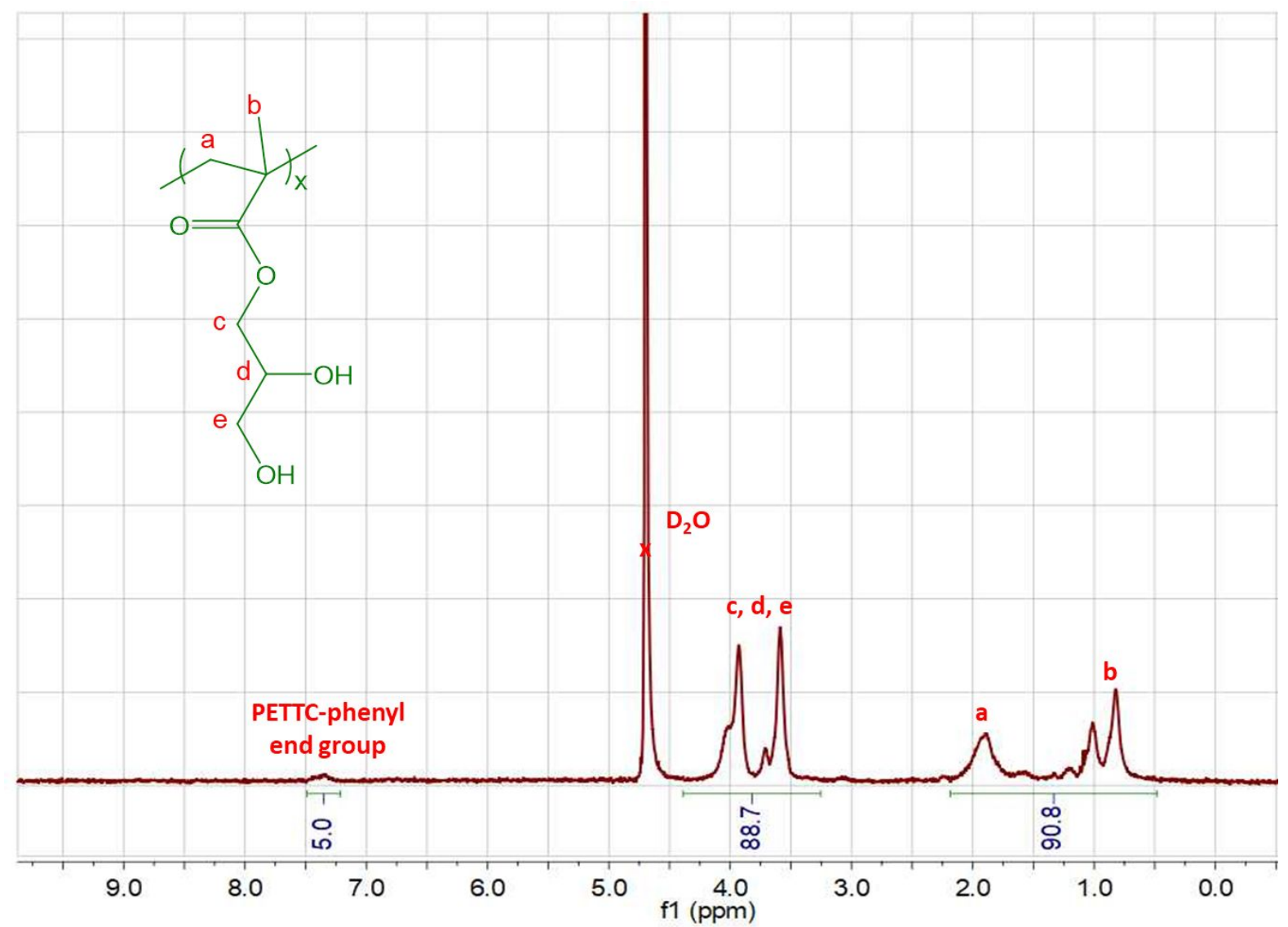

Figure S3. Chemical structure and ${ }^{1} \mathrm{H}$ NMR spectrum in $\mathrm{D}_{2} \mathrm{O}$ of $\mathrm{PGMA}_{18}$ mCTA (mCTA 1) 


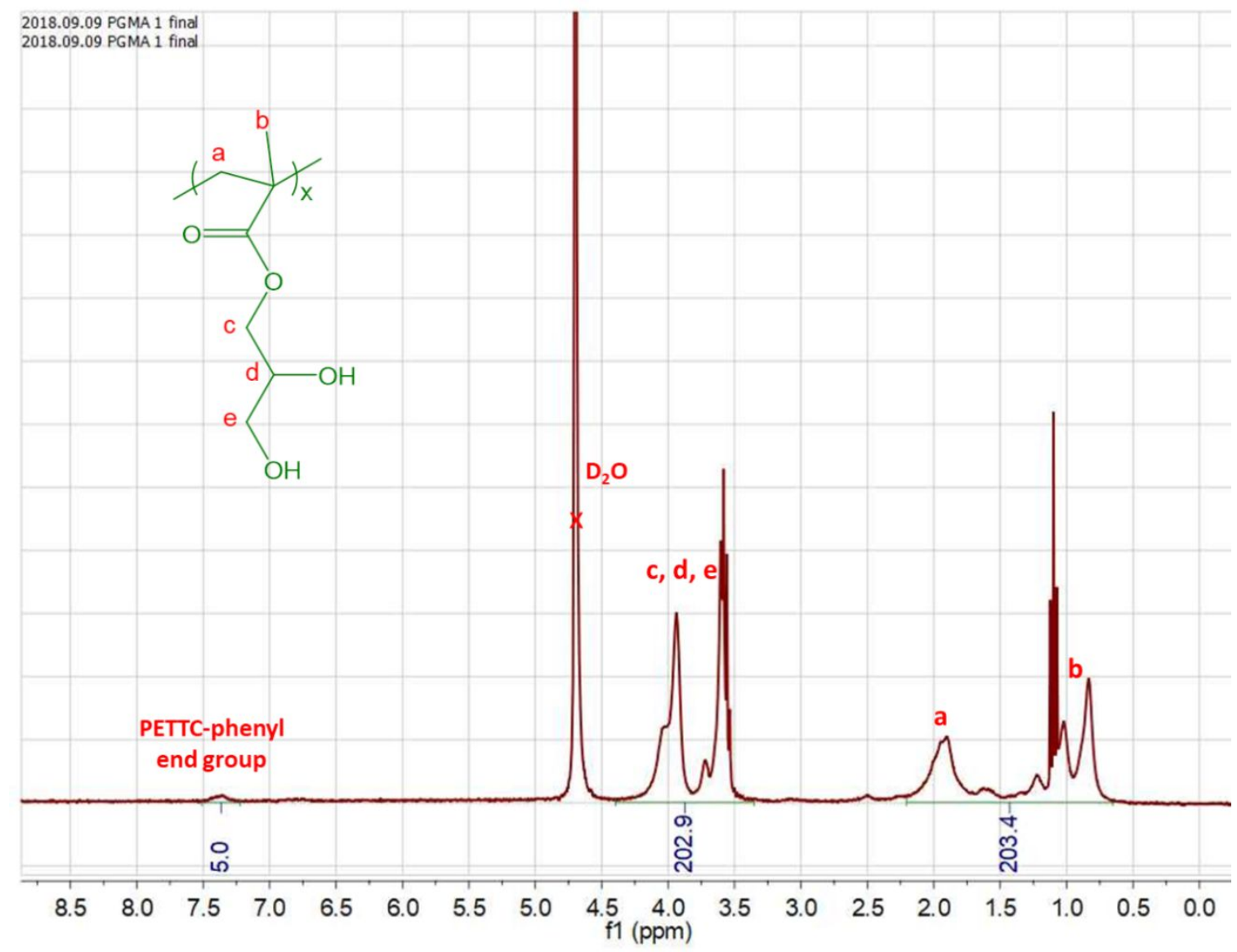

Figure S4. Chemical structure and ${ }^{1} \mathrm{H}$ NMR spectrum in $\mathrm{D}_{2} \mathrm{O}$ of $\mathrm{PGMA}_{40}$ mCTA (mCTA 2)

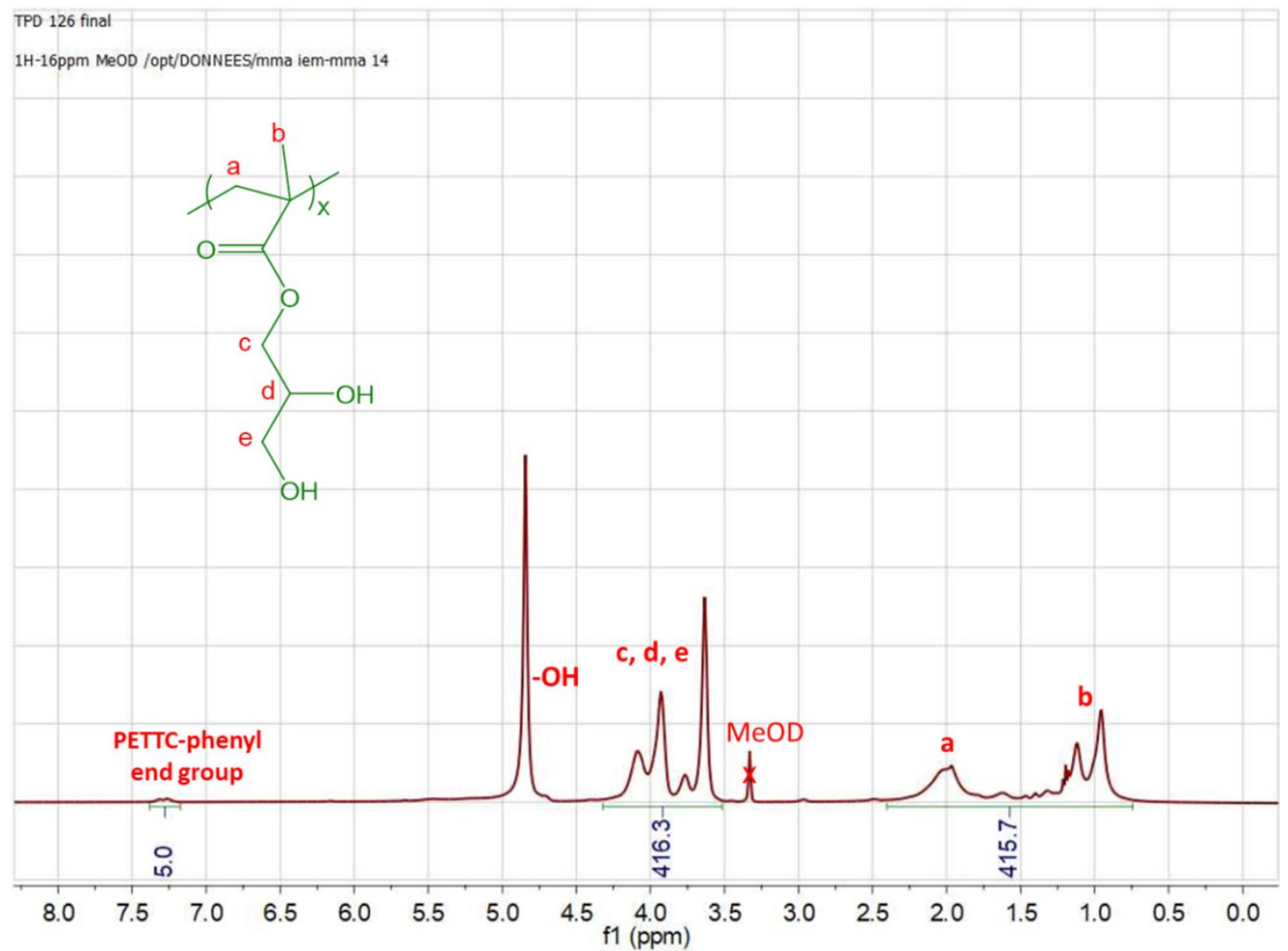

Figure S5. Chemical structure and ${ }^{1} \mathrm{H}$ NMR spectrum in Methanol-d4 of PGMA ${ }_{83}$ mCTA (mCTA 3) 


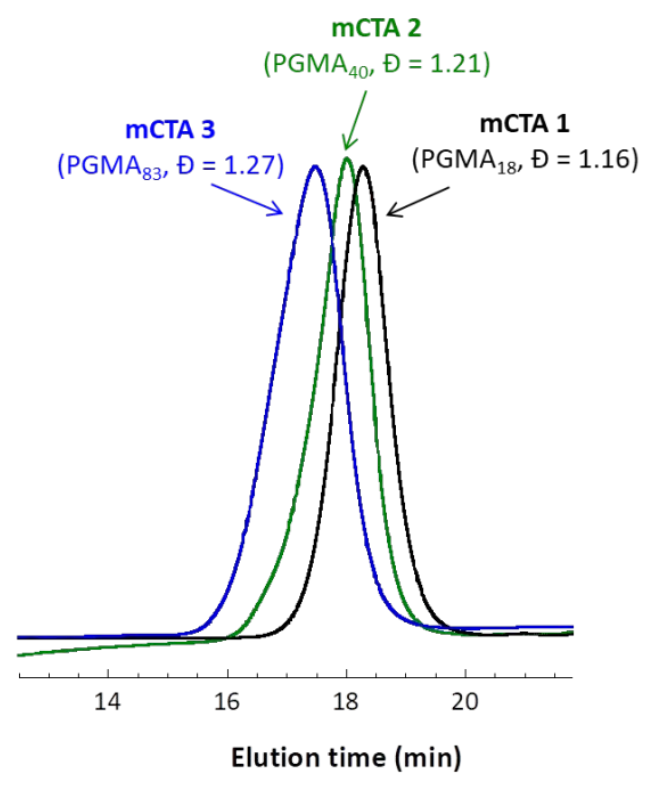

Figure S6. DMAc SEC data (refractive index detector) for the PGMA macro-CTAs
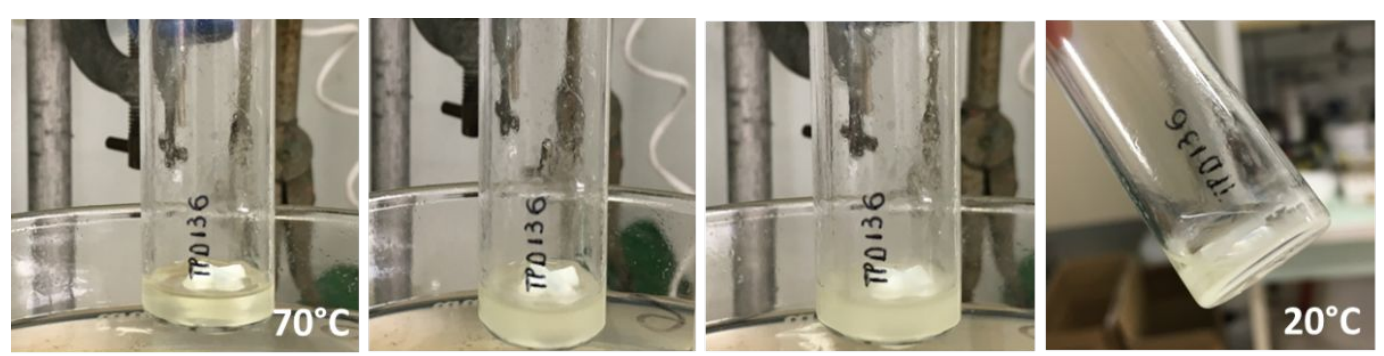

Heating up

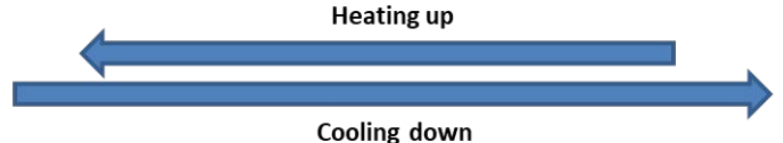

Cooling down

Figure S7. Photos taken for diblock copolymer PGMA $18-b-\mathrm{P}(\mathrm{MAm}-\mathrm{GFF})_{4}$ obtained by PISA carried out at $11.2 \% \mathrm{w} / \mathrm{w}$ in ethanol at $70^{\circ} \mathrm{C}$ and when cooling down to ambient temperature (ca. $20^{\circ} \mathrm{C}$ )

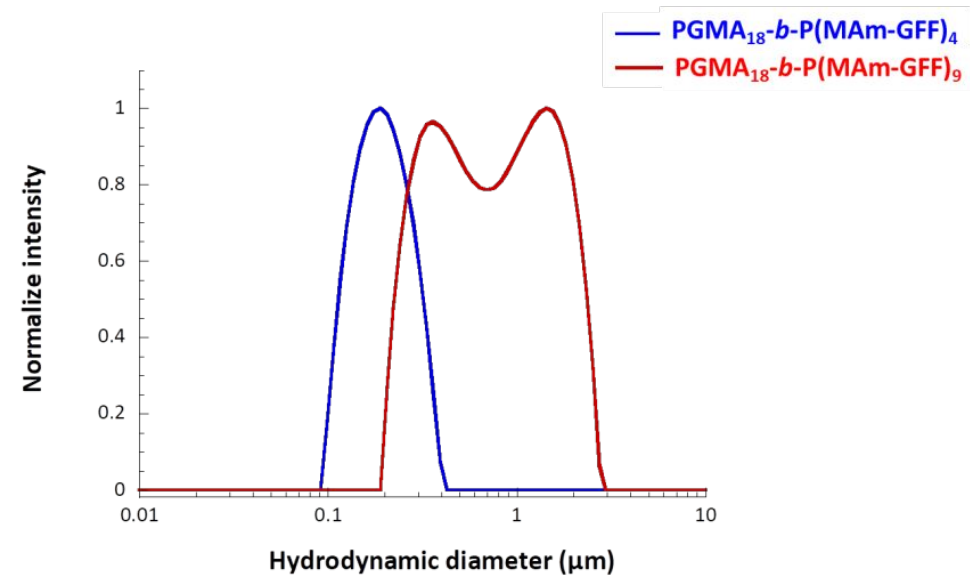

Figure S8. Intensity-average hydrodynamic diameter distribution of $\mathrm{PGMA}_{18}-b-\mathrm{P}(\mathrm{MAm}-\mathrm{GFF})_{4}$ and $\mathrm{PGMA} \mathrm{A}_{18}-b-\mathrm{P}(\mathrm{MAm}-\mathrm{GFF})_{9}$ suspension in ethanol at $0.112 \% \mathrm{w} / \mathrm{w}$ and $0.125 \% \mathrm{w} / \mathrm{w}$ repsectively 


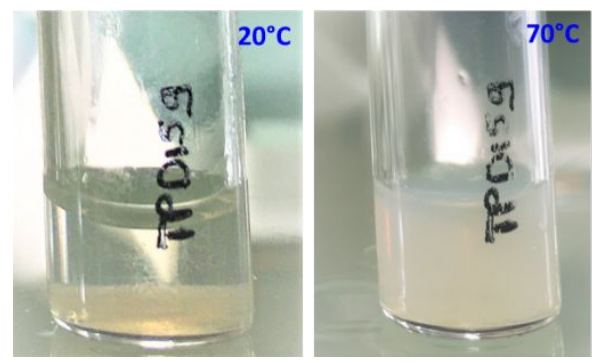

Figure S9. Diblock copolymer PGMA $18-b-\mathrm{P}\left((\mathrm{MAm}-\mathrm{GFF})_{9}-\mathrm{Co}-\mathrm{GMA}_{48}\right)$ obtained by $\mathrm{PISA}$ carried out at $15 \% \mathrm{w} / \mathrm{w}$ in ethanol at $70^{\circ} \mathrm{C}$ : on the left: after cooling from $70^{\circ} \mathrm{C}$ to $20^{\circ} \mathrm{C}$ and on the right: heating it up again from $20^{\circ} \mathrm{C}$ to $70^{\circ} \mathrm{C}$ (right)

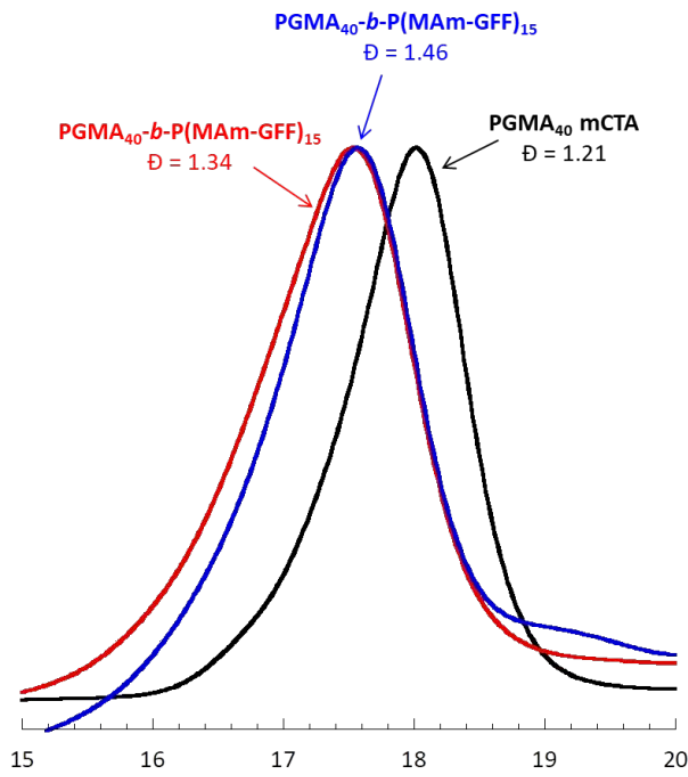

Elution Time $(\mathrm{min})$

Figure S10. DMAc SEC chromatograms (refractive index detector) of mCTA 2 (PGMA 40 ) and diblock copolymers PGMA $40-b$-P(MAmGFF) ${ }_{15}$ prepared via RAFT-mediated PISA in $1 / 1 \mathrm{v} / \mathrm{v}$ and $1 / 2 \mathrm{v} / \mathrm{v}$ water/acetonitrile mixtures (red and blue respectively)

Table S1. Summary of the conditions and results of RAFT-PISAs to synthese the diblock copolymers in this work

\begin{tabular}{|c|c|c|c|c|c|c|c|}
\hline Products & Solvent & $\begin{array}{l}\text { Visual } \\
\text { aspect at } \\
\text { starting } \\
\text { time of } \\
\text { PISA } \\
\text { (at } 70^{\circ} \mathrm{C} \text { ) }\end{array}$ & $\begin{array}{c}\text { Solids } \\
\text { content } \\
(\%)\end{array}$ & $\begin{array}{c}\text { Initial ratio } \\
{[\mathrm{mCTA}]_{0}:[\text { peptide }]_{0}:} \\
{[\mathrm{ACVA}]_{0}} \\
\text { or } \\
{[\mathrm{mCTA}]_{0}:[\text { peptide }]_{0}:} \\
{[\mathrm{GMA}]_{0}:[\mathrm{ACVA}]_{0}} \\
\text { or } \\
{[\mathrm{mCTA}]_{0}:[\text { peptide }]_{0}:} \\
{[\mathrm{HPMA}]_{0}:[\mathrm{ACVA}]_{0}} \\
\end{array}$ & $\begin{array}{c}\text { Monomer } \\
\text { peptide } \\
\text { conversion } \\
(\%)\end{array}$ & $\begin{array}{l}\bigoplus_{\text {GPC }} \\
\text { (DMAC) }\end{array}$ & $\begin{array}{c}\text { Visual } \\
\text { aspect at } \\
\text { ending time } \\
\text { of PISA } \\
\text { (at } 70^{\circ} \mathrm{C} \text { ) }\end{array}$ \\
\hline Macro-CTA 1: PGMA 18 & - & - & - & - & - & 1.16 & - \\
\hline $\mathrm{PGMA}_{18}-b-\mathrm{P}(\mathrm{MAm}-\mathrm{GFF})_{4}$ & Ethanol & Solution & $5 \%$ & $1: 5: 0.2$ & $45 \%$ & - & $\begin{array}{l}\text { Clear } \\
\text { solution }\end{array}$ \\
\hline $\mathrm{PGMA}_{18}-b-\mathrm{P}(\mathrm{MAm}-\mathrm{GFF})_{4}$ & Ethanol & Emulsion & $11.2 \%$ & $1: 5: 0.2$ & $87 \%$ & 1.17 & $\begin{array}{c}\text { Turbid } \\
\text { suspension }\end{array}$ \\
\hline $\mathrm{PGMA}_{18}-b-\mathrm{P}(\mathrm{MAm}-\mathrm{GFF})_{9}$ & Ethanol & Emulsion & $12.5 \%$ & $1: 10: 0.2$ & $92 \%$ & 1.28 & $\begin{array}{c}\text { Turbid } \\
\text { suspension }\end{array}$ \\
\hline $\begin{array}{c}\mathrm{PGMA}_{18}-b-\mathrm{P}\left((\mathrm{MAm}-\mathrm{GFF})_{9}-\mathrm{CO}-\right. \\
\left.\mathrm{GMA}_{48}\right)\end{array}$ & Ethanol & Emulsion & $15 \%$ & $1: 10: 48: 0.2$ & $90 \%$ & 1.33 & $\begin{array}{c}\text { Turbid } \\
\text { suspension }\end{array}$ \\
\hline
\end{tabular}




\begin{tabular}{|c|c|c|c|c|c|c|c|}
\hline $\begin{array}{c}\mathrm{PGMA}_{18}-b-\mathrm{P}\left((\mathrm{MAm}-\mathrm{GFF})_{9}-\mathrm{CO}-\right. \\
\left.\mathrm{HPMA}_{61}\right)\end{array}$ & Ethanol & Emulsion & $15 \%$ & $1: 10: 61: 0.2$ & $90 \%$ & 1.38 & $\begin{array}{c}\text { Clear } \\
\text { dispersion }\end{array}$ \\
\hline $\begin{array}{c}\mathrm{PGMA}_{18}-b-\mathrm{P}\left((\mathrm{MAm}-\mathrm{GFF})_{19}-\mathrm{CO}-\right. \\
\left.\mathrm{HPMA}_{50}\right)\end{array}$ & Ethanol & Emulsion & $15 \%$ & $1: 20: 50: 0.2$ & $95 \%$ & 1.32 & $\begin{array}{c}\text { Clear } \\
\text { dispersion }\end{array}$ \\
\hline $\mathrm{PGMA}_{18}-b-\mathrm{P}(\mathrm{MAm}-\mathrm{FGD})_{10}$ & Water & Solution & $10 \%$ & $1: 10: 0.2$ & $100 \%$ & 1.24 & $\begin{array}{c}\text { Turbid } \\
\text { suspension }\end{array}$ \\
\hline Macro-CTA 2: PGMA 40 & - & - & - & - & - & 1.21 & - \\
\hline $\mathrm{PGMA}_{40}-b-\mathrm{PMAGFF}_{8}$ & Ethanol & Emulsion & $12 \%$ & $1: 10: 0.2$ & $86 \%$ & 1.34 & $\begin{array}{c}\text { Turbid } \\
\text { suspension }\end{array}$ \\
\hline $\mathrm{PGMA}_{40}-b-\mathrm{PMAGFF}_{15}$ & $\begin{array}{c}\mathrm{H}_{2} \mathrm{O} / \mathrm{ACN} \\
1 / 1 \mathrm{v} / \mathrm{v}\end{array}$ & Solution & $10 \%$ & $1: 20: 0.2$ & $69 \%$ & 1.34 & $\begin{array}{c}\text { Clear } \\
\text { dispersion }\end{array}$ \\
\hline $\mathrm{PGMA}_{40}-b-\mathrm{PMAGFF}{ }_{15}$ & $\begin{array}{c}\mathrm{H}_{2} \mathrm{O} / \mathrm{ACN} \\
1 / 2 \mathrm{v} / \mathrm{v}\end{array}$ & Solution & $10 \%$ & $1: 20: 0.2$ & $72 \%$ & 1.46 & $\begin{array}{c}\text { Clear } \\
\text { dispersion }\end{array}$ \\
\hline $\mathrm{PGMA}_{40}-b-\mathrm{P}(\mathrm{MAm}-\mathrm{FGD})_{20}$ & Water & Solution & $10 \%$ & $1: 20: 0.2$ & $100 \%$ & 1.24 & $\begin{array}{c}\text { Turbid } \\
\text { suspension }\end{array}$ \\
\hline Macro-CTA 3: PGMA & - & - & - & - & - & 1.27 & - \\
\hline $\mathrm{PGMA}_{83}-b-\mathrm{PMAGFF}_{6}$ & Ethanol & Emulsion & $12 \%$ & $1: 6: 0.2$ & $90 \%$ & 1.26 & $\begin{array}{c}\text { Turbid } \\
\text { suspension }\end{array}$ \\
\hline $\mathrm{PGMA}_{83}-b-\mathrm{PMAGFF}_{10}$ & Ethanol & Emulsion & $12 \%$ & $1: 10: 0.2$ & $95 \%$ & 1.42 & $\begin{array}{c}\text { Turbid } \\
\text { suspension }\end{array}$ \\
\hline $\mathrm{PGMA}_{83}-b-\mathrm{P}(\mathrm{MAm}-\mathrm{FGD})_{20}$ & Water & Solution & $10 \%$ & $1: 20: 0.2$ & $100 \%$ & 1.29 & $\begin{array}{c}\text { Clear } \\
\text { dispersion }\end{array}$ \\
\hline
\end{tabular}

